Research Article

\title{
Vibration Characteristics and Simulation Verification of the Dual-Rotor System for Aeroengines with Rub-Impact Coupling Faults
}

\author{
Pingping Ma, ${ }^{1}$ Mingxin Shan, ${ }^{1}$ Jingyu Zhai, ${ }^{1}$ Hao Zhang, ${ }^{2}$ and Qingkai Han ${ }^{1}{ }^{1}$ \\ ${ }^{1}$ School of Mechanical Engineering, Dalian University of Technology, Dalian 116024, China \\ ${ }^{2}$ School of Mechanical Engineering, Liaoning University of Technology, Jinzhou 121000, China \\ Correspondence should be addressed to Qingkai Han; qk.han@hotmail.com
}

Received 20 October 2020; Revised 25 March 2021; Accepted 30 March 2021; Published 27 April 2021

Academic Editor: Giosuè Boscato

Copyright (c) 2021 Pingping Ma et al. This is an open access article distributed under the Creative Commons Attribution License, which permits unrestricted use, distribution, and reproduction in any medium, provided the original work is properly cited.

To study the rub-impact fault between the dynamic and static parts of the rotor system of aeroengines, the dual-rotor system of a typical aeroengine is introduced and taken as the research object. The analytical kinetic model is established based on the Lagrange equation considering the structural characteristics of the dual-rotor system, the coupling effect of the intermediate bearing, and the rub-impact fault between the high-pressure turbine disc and the casing. The dynamic characteristics of the dual-rotor system under the rub-impact fault are analyzed, and the change rule of the rub-impact shape is obtained. The vibration coupling and transfer among the high-pressure rotor and the low-pressure rotor are revealed. The influence of the unbalanced position and the speed of high and low rotors on the vibration response of the dual rotor is obtained. The sensitivity of the vibration response of the dual rotor at different test points to rub-impact stiffness, clearance, and friction coefficient is compared. The simulation model is established based on the rigid-flexible coupling multibody dynamic simulation platform. The analytical results and simulation results are compared, which have a good consistency. The theoretical research can deepen the understanding of the nature and law of aeroengine rotor operation, expose the possible faults and design defects, greatly improve the development efficiency and quality, reduce repeated physical tests, reduce the development risk and cost, and accelerate the development process. This study can provide a theoretical basis for the monitoring and diagnosis of engine rub-impact faults and provide theoretical and practical reference for the establishment of the vibration fault test and analysis method system.

\section{Introduction}

As the 'heart' of an aircraft, the aeroengine is the decisive factor of aircraft safety, reliability, and operational performance. With the increasing requirements of high speed and the high thrust-weight ratio of aeroengines, the clearance between the rotor and stator decreases, which increases the possibility of a rub-impact fault. The rub-impact fault has become one of the most common faults of the dual-rotor system in aeroengines. It is one of the causes of the complex nonlinear vibration of the dual-rotor system and an important reason for the instability of the rotor system. The rub-impact fault will not only lead to the increase of the rotor-stator clearance, bearing wear, and blade cracks but also may cause the rotor system motion instability and make the casing deform greatly, and the excessive vibration will seriously affect the working efficiency of the engine. The vibration of the unit will increase dramatically, which will affect the service life of the unit. In serious cases, it will cause permanent bending of the rotor and even cause fatal accidents. It is difficult to find out the cause of abnormal vibration before the machine stops for overhaul. Therefore, it is of great significance to explore the vibration characteristics of the rotor rub-impact, especially the early rub-impact characteristics, and detect these characteristics for avoiding rub-impact faults and secondary faults.

Many theoretical research studies on the aeroengine rotor system have been carried out by scholars at home and abroad. Representative results include the long-term research achievements and contributions of Professor 
Yushu Chen and Huabiao Zhang [1-3] of Harbin Institute of Technology, Litang Yan [4] of Beijing University of Aeronautics and Astronautics, Mingfu Liao [5-7] of Northwest Polytechnic University, Qingkai Han [8-10] of Dalian University of Technology, Guihuo Luo [11], and Guo Chen [12] of Nanjing University of Aeronautics and Astronautics. Wang [13] took a dual rotor as the research object, established a dynamic model considering the friction between the rotor and the casing, studied the nonlinear problem of the rub-impact rotor, and used the nonlinear rotor dynamics theory to analyze the model of the rub-impact rotor system and its chaotic motion evolution law. Liu et al. [14] established the dynamic equation of an aeroengine dual-rotor system with a rubimpact fault by using the Lagrange equation, simulated the rub-impact fault through numerical calculation, and proposed the effectiveness and reliability of the method of combining spectrum analysis and wavelet transform to diagnose the rub-impact fault of the rotor and stator. Considering the elastic deformation, contact penetration, and elastic damping support during the collision between the casing and the disc, Wang et al. [15] established the dynamic model of the dynamic and static rub-impact of the dual-rotor system by applying Hertz contact theory and Coulomb model and solved the dynamic response of the dual-rotor system under the rub-impact fault. The dual-rotor system testbed is established to carry out the dynamic and static rub-impact test, and it is proposed that the double-frequency and combined frequency components of the two excitation sources can be taken as the typical characteristics of the aeroengine dynamic and static rub-impact fault. Zhang et al. [16] took the dualrotor system of an aeroengine as the research object, established the coupled bending-torsion dynamic equation with rub-impact force by considering the force of the intermediate bearing, and calculated the vibration response of the dual-rotor under the rub-impact fault by using numerical methods. The frequency spectrum and bifurcation characteristics of the bending and torsional vibration are analyzed, and experimental research on the bending and torsional vibration is carried out based on the rotor test bench. The results show that the bending and torsional vibration have a similar characteristic frequency, but the torsional vibration characteristic frequency is more obvious, and the torsional vibration signal can be better used for rub-impact fault diagnosis. Ouyang and Yang [17] established the dynamic model of the dual-rotor system of the aeroengine without the intermediate bearing by using a lumped-mass method. The rotor rub-impact fault was simulated, and the vibration response of the rotor system under different rub-impact conditions was obtained. Zhang [18] established the dynamic model of the aeroengine dual-rotor-casing coupling system, solved the critical speed and vibration mode of the system, discussed the influence of support parameters and speed ratio on the critical speed and vibration mode, calculated the rub-impact response of the dual-rotor-casing coupling system, and studied the influence of different rub-impact degrees and unbalance on the dual-rotor rub-impact fault.
Liu [19] established the dynamic model of the dual-rotor system with a rub-impact fault and studied the vibration response of the dual-rotor system under the rub-impact fault. Compared with the unbalanced dynamic characteristics of the dual-rotor system, he found that the rubimpact fault makes the rotor system vibration response appear the combined frequency of rotation frequency, which makes the rotor system vibration appear nonlinear. The influence of the parameters such as the rub-impact clearance on the dynamic characteristics of the dual-rotor system was also studied, and the severity of the rub-impact fault can be judged according to it.

The dual-rotor system of aeroengines has a special structure. For example, the low-pressure rotor is supported by three fulcrums, and the high-pressure rotor and the lowpressure rotor are connected by an intermediate bearing. Although there have been some results on the dynamics of the dual-rotor system, the characteristics of dynamic coupling and vibration transmission of the dual-rotor system for aeroengines have not been studied in detail. According to the engineering observation, the sensitivity of the low-pressure rotor and the high-pressure rotor to the rub-impact is different, and the sensitivity of the rub-impact at different locations is analyzed in [20]. In this paper, the vibration sensitivity of different positions of the rotor with a rubimpact fault is studied by using the method of analysis and multibody dynamics simulation verification. The influence characteristics of rub-impact stiffness, clearance, and friction coefficient on the vibration response of the dual rotor are compared.

\section{Establishment of the Dynamic Model for the Dual-Rotor System}

Taking a typical aeroengine shown in Figure 1 in [20] as a prototype, a simplified model of the dual-rotor system as shown in Figure 2 is obtained according to the principle of similarity design. The main parts of the main structure of the dual-rotor system are the fan rotor, the low-pressure turbine rotor, the high-pressure rotor, turntable, support, and coupling. The low-pressure rotor is composed of a fan disc and one turbine disc. The total length of the low-pressure rotor is about $1261 \mathrm{~mm}$. It adopts the supporting form of three fulcrums, namely, a 1-1-1 support form. The front fulcrum of the fan and the rear fulcrum of the low-pressure turbine are elastic supports. The low-pressure turbine shaft is slender, and the fan rotor and the low-pressure turbine rotor are connected by a sleeve gear coupling which can transmit axial force and torque. The high-pressure rotor is composed of the compressor and one turbine, in which the support span is $580 \mathrm{~mm}$. The high-pressure compressor and the high-pressure turbine are rigidly connected through the hollow shaft, and the 1-0-1 two-point support mode is adopted. The front support of the high-pressure compressor is the elastic support, and the rear support is the intermediate bearing. The stiffness of each fulcrum is shown in Table 1. In order to simplify the structure, reduce the quality of the rotor system, and reduce the dynamic influence between the high- and low-pressure rotors, the rotor system 


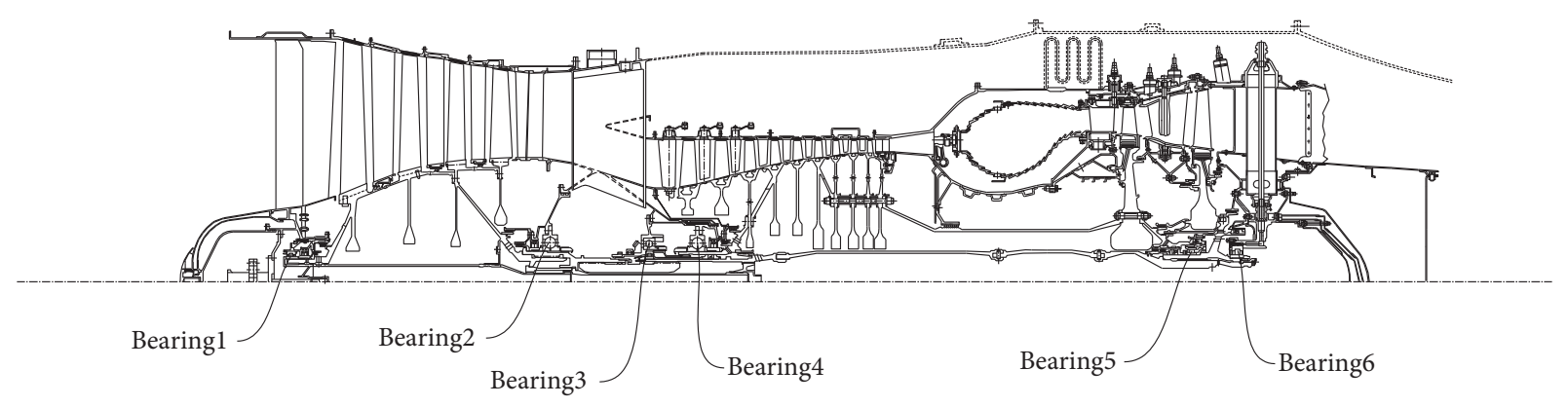

Figure 1: Structural sketch of a dual-rotor system for a typical aeroengine.

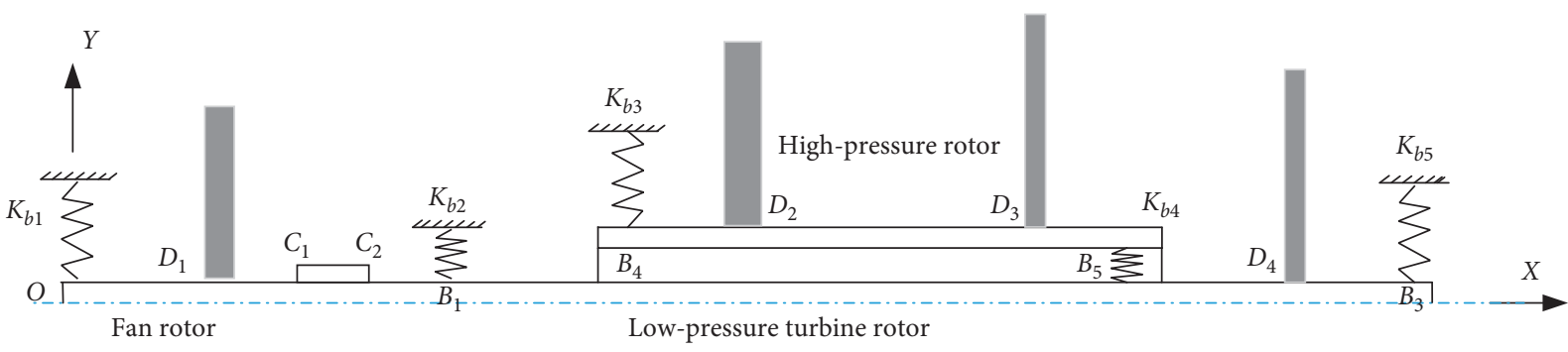

FIgURE 2: The diagram of the simplified dual-rotor model.

TABLE 1: Stiffness of the supports.

\begin{tabular}{lcccc}
\hline$K_{\mathrm{b} 1}$ & $K_{\mathrm{b} 2}$ & $K_{\mathrm{b} 3}$ & $K_{\mathrm{b} 4}$ & $K_{\mathrm{b} 5}$ \\
\hline $9 \times 10^{6} \mathrm{~N} / \mathrm{m}$ & $2.5 \times 10^{8} \mathrm{~N} / \mathrm{m}$ & $3 \times 10^{6} \mathrm{~N} / \mathrm{m}$ & $2.5 \times 10^{8} \mathrm{~N} / \mathrm{m}$ & $3 \times 10^{6} \mathrm{~N} / \mathrm{m}$ \\
\hline
\end{tabular}

adopts the intermediate bearing design with the highpressure rotor rear fulcrum as close as possible to the lowpressure turbine rear fulcrum. The high- and low-pressure rotors are coupled through the intermediate bearing. The rotor transmits the load through the fulcrum of another rotor. Therefore, the dynamic characteristics of the dualrotor system are not only affected by the high- and lowpressure rotors but also have some unique vibration characteristics.

\section{Dynamic Model of the Dual Rotor with the Rub-Impact Fault}

The analytical equations of multisupport motion of the dualrotor system are derived utilizing the Lagrange method, and the governing differential equations of the dual-rotor system considering the axial and bending vibration but not torsional vibration are obtained. In the model, the four discs, the fan shaft, and the high-pressure shaft are considered to be rigid, while the slender shaft of the low-pressure turbine is considered as elastic. The support of the rotor system is considered to be elastic, and the speed of the rotating shaft is considered to be constant. The rubbing fault often occurs between the high-pressure rotor and the casing [21]. In this study, only the rub-impact between the high-pressure turbine disc and the stator casing is considered.

The fixed coordinate system of the system is $o x y$, and the dynamic equation of the whole system is as follows:

$$
\mathbf{M} \ddot{q}+\mathbf{C} \dot{q}+\mathbf{G} \dot{q}+\mathbf{K q}=\mathbf{F},
$$

where $\mathbf{M}, C, \mathbf{G}, \mathbf{K}$, and $\mathbf{F}$ are the mass matrix, damping matrix, gyro force matrix, stiffness matrix, and generalized force matrix, respectively.q is the generalized coordinate vector. Among them,

$$
\begin{aligned}
& \mathbf{q}=\left\{\begin{array}{lllllllllllllllll}
y_{1} & z_{1} & \theta_{y_{1}} & \theta_{z_{1}} & y_{2} & z_{2} & \theta_{y_{2}} & \theta_{z_{2}} & y_{3} & z_{3} & \theta_{y_{3}} & \theta_{z_{3}} & y_{4} & z_{4} & \theta_{y_{4}} & \theta_{z_{4}}
\end{array}\right\}, \\
& \mathbf{F}=\left\{\begin{array}{llllllllllllllllll}
F_{1 y} & F_{1 z} & 0 & 0 & F_{2 y} & F_{2 z} & 0 & 0 & F_{3 y} & F_{3 z} & 0 & 0 & F_{4 y}+F_{R y} & F_{4 z}+F_{R z} & 0 & 0
\end{array}\right\},
\end{aligned}
$$

where $F_{i y}, F_{i z}(i=1 \sim 4)$ are the component of unbalanced excitation force in the $y$-direction and $z$-direction by four discs and $F_{R y}, F_{R z}$ are the component of rub-impact force in the $y$-direction and $z$-direction. 


\section{Unbalanced Model}

The unbalance of the dual-rotor system mainly includes the fan disc unbalance, the low-pressure turbine disc unbalance, the high-pressure compressor disc unbalance, and the highpressure turbine disc unbalance. The components of the centrifugal force produced by the unbalanced mass of each disc in the $y$-direction and $z$-direction are as follows:

$$
\left\{\begin{array}{l}
\mathrm{F}_{i y}=m_{e i} \Omega_{\mathrm{i}}{ }^{2} \cos \left(\Omega_{i} \mathrm{t}+\phi_{i}\right) \\
\mathrm{F}_{i z}=m_{e i} \Omega_{\mathrm{i}}{ }^{2} \sin \left(\Omega_{i} \mathrm{t}+\phi_{i}\right)
\end{array}, \quad i=1-4,\right.
$$

where $m_{e i}$ is the unbalanced mass, and the unit is $\mathrm{Kg} \cdot m . \phi_{i}$ is the initial phase angle of the disc centroid, and the unit is rad. $\Omega_{i}$ is the rotational angular velocity of the low- and high-pressure rotors, and the unit is $\mathrm{rad} / \mathrm{s}$.

\section{Rub-Impact Model}

The schematic diagram of the local rub-impact between the rotor and stator is shown in Figure 3. $F_{\mathrm{y}}$ and $F_{z}$ stand for the normal force and tangential force exerted on the disc by the rubbing plate, respectively. $\varphi$ denotes the angle of the rubbing plate normal direction and the $x$-axis, and $e$ is the moving distance of the rotor axis. The deformation of the rubbing plate caused by the rub-impact between the disc and rubbing plate is supposed to be linear. $k_{c}$ is the radial stiffness of the rubbing plate. $f_{r}$ and $\delta$ are the friction coefficient at the rubbing point and the clearance between the rubbing plate and the disc, respectively. Function $H$ means that when $(z-\delta)$ is less than 0 , it is equal to 0 , and otherwise, it is equal to 1 . The concrete expression is as follows:

$$
\left\{\begin{array}{l}
F_{R z}=-k_{r}(z-\delta) H \\
F_{R y}=F_{R z} f_{r}=-k_{r}(z-\delta) H f_{r}
\end{array}\right.
$$

Rayleigh damping is adopted in the damping model, and the structure is as follows:

$$
\mathrm{C}=\alpha \mathrm{M}+\beta \mathbf{K} .
$$

The Rayleigh damping matrix is a linear combination of the mass matrix and the stiffness matrix, where $\alpha$ and $\beta$ are damping coefficients, which are related to the modal damping ratio $\xi$ of the structure. The calculation formula is as follows:

$$
\begin{aligned}
& \alpha=2 \omega_{1} \omega_{2} \frac{\left(\xi_{1} \omega_{2}-\xi_{2} \omega_{1}\right)}{\omega_{2}^{2}-\omega_{1}^{2}}, \\
& \beta=2 \frac{\left(\xi_{2} \omega_{2}-\xi_{1} \omega_{1}\right)}{\left(\omega_{2}^{2}-\omega_{1}^{2}\right)} .
\end{aligned}
$$

After derivation, other matrices can be easily obtained.

\section{Inherent Characteristics of the Dual- Rotor System}

According to matrices $\mathbf{M}, \mathbf{G}$, and $\mathbf{K}$ in formula (1), the modal frequency and modal shape of the rotor can be obtained. The displacement of the rotor system is written as follows:

$$
\mathbf{q}=\mathbf{q}_{0} e^{i \omega_{n} t},
$$

where $\omega_{n}$ is the whirl frequency of the rotor system; then, equation (3) can be written as

$$
-\omega_{n}^{2} \mathbf{M} \mathbf{q}_{0}+i \omega_{n} \Omega \mathbf{G q}_{0}+\mathbf{K} \mathbf{q}_{0}=0 .
$$

When calculating the critical speed, the whirl frequency and rotation frequency of the rotor are equal; then, the above formula can be written as

$$
(\mathbf{M}-i \mathbf{G})^{-1} \mathbf{K} \mathbf{q}_{0}=\omega_{n}^{2} \mathbf{q}_{0} .
$$

$\omega_{n}^{2}$ is the eigenvalue of matrix $(\mathbf{M}-i \mathbf{G})^{-1} \mathbf{K}$. The eigenvalue and eigenvector of matrix $(\mathbf{M}-i \mathbf{G})^{-1} \mathbf{K}$ are obtained by MATLAB programming. The square and eigenvector of the eigenvalue are the modal frequency and mode shape of the rotor system. The natural frequencies and vibration modes of the dual-rotor system are shown in Figure 4.

The model parameters of the simplified dual-rotor system are shown in Tables 2-4, in which four equivalent discs are shown in Table 2, the equivalent parameters of the rotating shaft are shown in Table 3, and the distance parameters are shown in Table 4.

It can be seen from Figure 4 that the first and second modes of the low-pressure rotor are mainly the first bending mode of the low-pressure rotor turbine section, the first mode of the high-pressure rotor is the translation mode, and the second mode is the pitching vibration.

\section{Analysis Results}

7.1. Method of Calculation. In this paper, the Newmark- $\beta$ method is used to solve the vibration response of the dualrotor system under the rub-impact fault. Newmark- $\beta$ method is an integral dynamic numerical analysis method. Different from the analytical method and numerical integration method, it gives the complex calculation task to the computer through simple programming, which is convenient and can achieve good accuracy. The Newmark- $\beta$ integration method is a kind of step-by-step integration method. It can set the time interval between every two calculation substeps and calculate the response result of the next calculation substep according to the previous calculation results. As long as the parameters are set reasonably, good convergence can be achieved. 


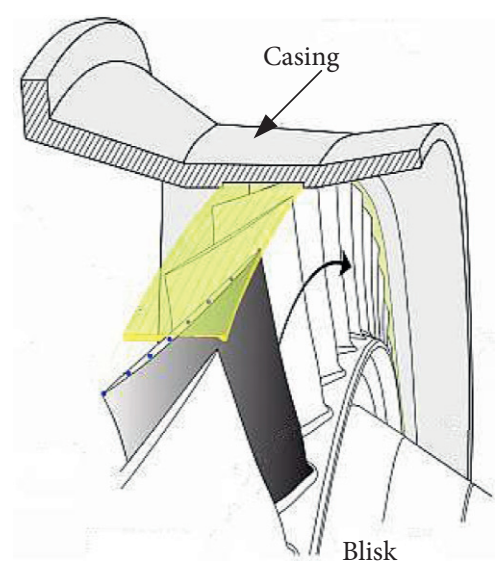

(a)

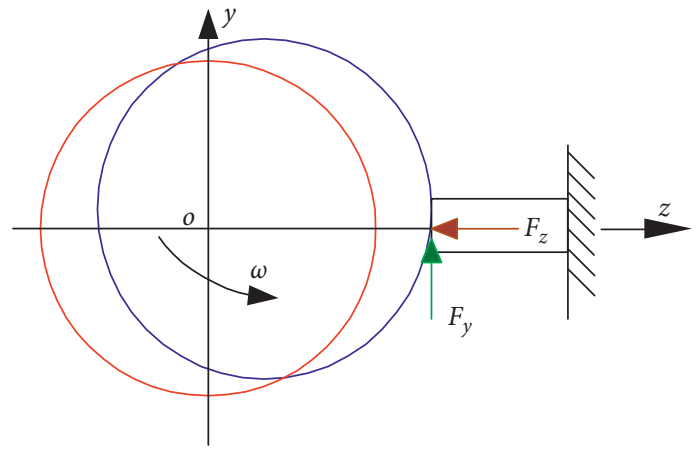

(b)

Figure 3: The dynamic model of fixed-point rubbing. (a) Schematic diagram of rubbing between the casing and blisk. (b) Mechanical model of fixed-point rub-impact.

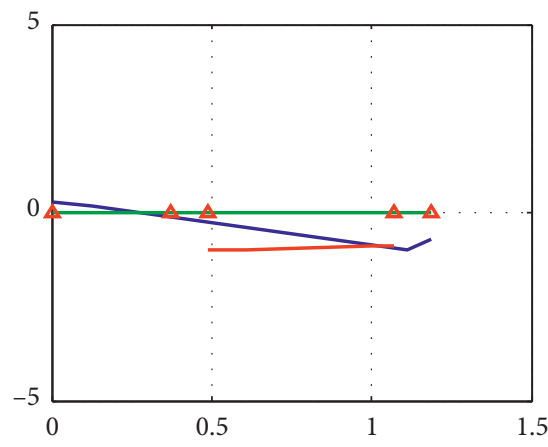

(a)

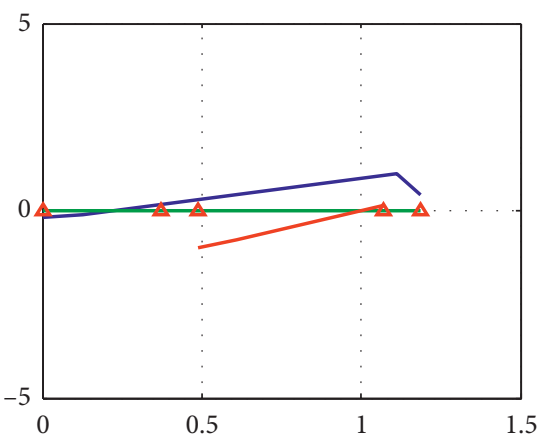

(b)

Figure 4: Vibration modes' diagram of the dual-rotor system. (a) First-order vibration $(58.8 \mathrm{~Hz})$. (b) Second-order vibration (75.4 Hz).

TABle 2: Parameters of four equivalent discs.

\begin{tabular}{lccccc}
\hline Disc & $h(\mathrm{~mm})$ & $D(\mathrm{~mm})$ & $d(\mathrm{~mm})$ & $m(\mathrm{Kg})$ & $J(\mathrm{Kg} \cdot \mathrm{m} 2)$ \\
\hline$D_{1}$ & 18 & 330 & 35 & 14.0 & $J_{\mathrm{p}}=0.164, J_{\mathrm{d}}=0.101$ \\
$D_{2}$ & 10 & 316 & 48 & 11.3 & $J_{\mathrm{p}}=0.059, J_{\mathrm{d}}=0.060$ \\
$D_{3}$ & 35 & 305 & 73 & 20 & $J_{\mathrm{p}}=0.230, J_{\mathrm{d}}=0.120$ \\
$D_{4}$ & 14 & 304 & 62 & 10 & $J_{\mathrm{p}}=0.102, J_{\mathrm{d}}=0.050$ \\
\hline
\end{tabular}

TABLE 3: Parameters of the equivalent rotation shaft.

\begin{tabular}{|c|c|c|c|}
\hline Shaft number & $D(\mathrm{~mm})$ & $d(\mathrm{~mm})$ & $L(\mathrm{~mm})$ \\
\hline The shaft of the low-pressure compressor & 30 & 0 & 381 \\
\hline The shaft of the low-pressure turbine & 30 & 0 & 923 \\
\hline The shaft of the high-pressure rotor & 65 & 40 & 680 \\
\hline
\end{tabular}

TABLE 4: Dimension parameters of the simplified dual-rotor system.

\begin{tabular}{lcccccccccc}
\hline Parameter name & $O D_{1}$ & $B_{2} D_{2}$ & $B_{3} D_{3}$ & $D_{3} B_{4}$ & $D_{4} B_{4}$ & $C_{1} C_{2}$ & $D_{1} C_{1}$ & $O B_{3}$ & $B_{4} B_{5}$ & $B_{2} B_{5}$ \\
\hline Numerical value $(\mathrm{mm})$ & 127 & 737 & 116 & 459 & 69 & 70 & 138 & 1186 & 581 & 814 \\
\hline
\end{tabular}




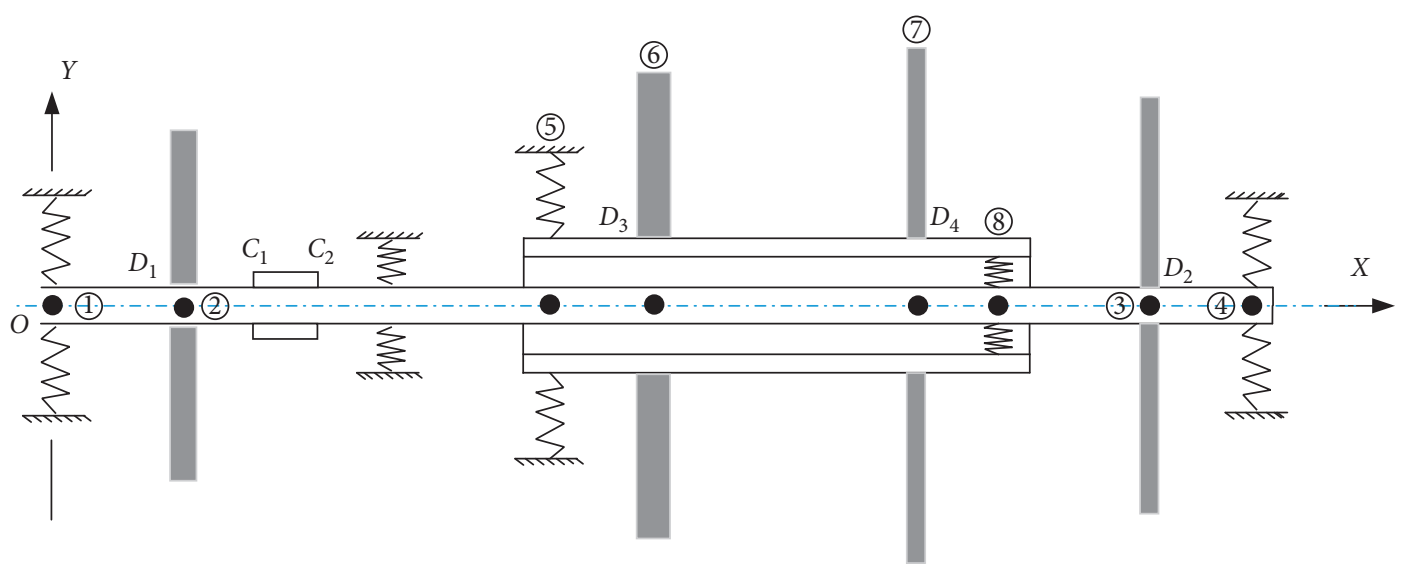

FIGURE 5: The arrangement of vibration measuring points of the dual-rotor system.

TABle 5: Parameter setting of the rub-impact model.

\begin{tabular}{|c|c|c|c|c|}
\hline Parameter & $\mathrm{I}$ & II & III & IV \\
\hline Rub-impact stiffness & $1 \times 10^{6} \mathrm{~N} / \mathrm{m}$ & $7 \times 10^{6} \mathrm{~N} / \mathrm{m}$ & $3 \times 10^{7} \mathrm{~N} / \mathrm{m}$ & 0 \\
\hline Friction coefficient & 0.4 & 0.4 & 0.6 & 0 \\
\hline Rub-impact clearance & $1 \times 10^{-7} \mathrm{~m}$ & $1 \times 10^{-6} \mathrm{~m}$ & $1 \times 10^{-7} \mathrm{~m}$ & 0 \\
\hline LPC unbalance & $500 \mathrm{~g} \mathrm{~mm}$ & $500 \mathrm{~g} \mathrm{~mm}$ & $500 \mathrm{~g} \mathrm{~mm}$ & $500 \mathrm{~g} \mathrm{~mm}$ \\
\hline HPC unbalance & $500 \mathrm{~g} \mathrm{~mm}$ & $500 \mathrm{~g} \mathrm{~mm}$ & $500 \mathrm{~g} \mathrm{~mm}$ & $500 \mathrm{~g} \mathrm{~mm}$ \\
\hline
\end{tabular}

To study the vibration response of the dual-rotor system under the rub-impact fault, four measuring points 1-4 are selected on the low-pressure rotor, among which No. 1 measuring point is 1 \# fulcrum, No. 2 measuring point is the center of mass of the LPC (the fan disc), No. 3 measuring point is the center of mass of the LPT (the low-pressure turbine disc), and No. 4 measuring point is 6 \# fulcrum. Four measuring points $5-8$ are selected on the outer rotor, among which No. 5 measuring point is $4 \#$ fulcrum, No. 6 measuring point is the center of mass of the HPC (the high-pressure compressor), No. 7 measuring point is the center of mass of the HPT (the high-pressure turbine disc), and No. 8 measuring point is $5 \#$ intermediary support. The arrangement of vibration measuring points of the dual-rotor system is shown in Figure 5.

\subsection{Vibration Characteristics of the Dual Rotor with HPT Rubbing}

7.2.1. Influence of Rub-Impact Stiffness on the Vibration Response. Based on the analysis method, the vibration response of the dual-rotor system under the rub-impact fault is analyzed by the Newmark- $\beta$ method. Speed setting: lowpressure speed $N 1=170 \mathrm{~Hz}$; high-pressure speed $N 2=221.67 \mathrm{~Hz}$. As shown in Table 5, the vibration characteristics of the dual-rotor system under four different parameter settings are analyzed, and the vibration time domain, frequency spectrum, and axis orbit of eight measuring points are obtained. The vibration response of the dual-rotor system under three different rub-impact parameter settings is shown in Figures 6-8.
Based on the analysis of the unbalance vibration characteristics of the dual-rotor system in [22], it can be seen that only high- and low-pressure rotating frequencies $N 1$ and N2 appear in the unbalanced vibration response of the dual-rotor system. In this paper, the vibration trajectories of the low-pressure and high-pressure rotors are obtained as shown in Figure 9, under condition IV in Table 5.

Comparing the vibration results in Figures 6-9 of each measuring point with or without rub-impact, the following can be seen:

(1) Rub-impact fault makes the vibration response of the dual-rotor system have nonlinear characteristics. The dynamic response of the rotor also contains the combined and division components of the speed frequency, and the occurrence of the rub-impact fault makes the axis track no longer a regular circle.

(2) It can be seen from the time-domain diagram that the occurrence of the rub-impact fault increases the amplitude of the rotational frequency of the dualrotor system.

(3) Compared with Figures 7-9, it can be seen that, with the increase of rub-impact stiffness, the amplitude of rub-impact spectrum components increases, and the component of the spectrum becomes more complex. In the case of the slight rub-impact, there are no other components in the vibration spectrum of each measuring point except the rotational frequency and $N 2-N 1$. With the increase of rub-impact degree, $(2 N 2-N 1), 1 / 2 N 2,2 N 1, N 1+N 2,2 N 2$, etc., appear in the frequency components. 

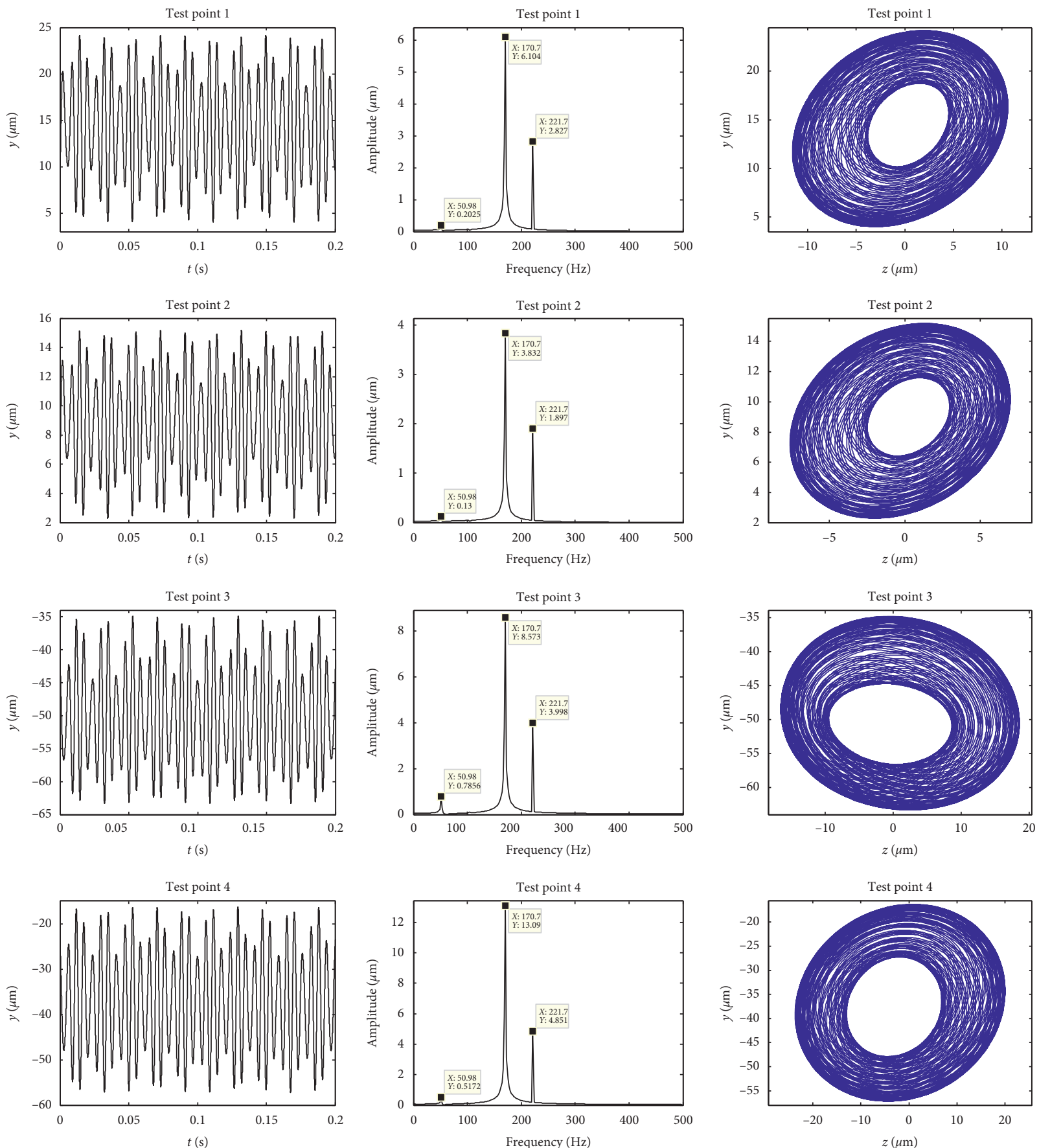

(a)

Figure 6: Continued. 

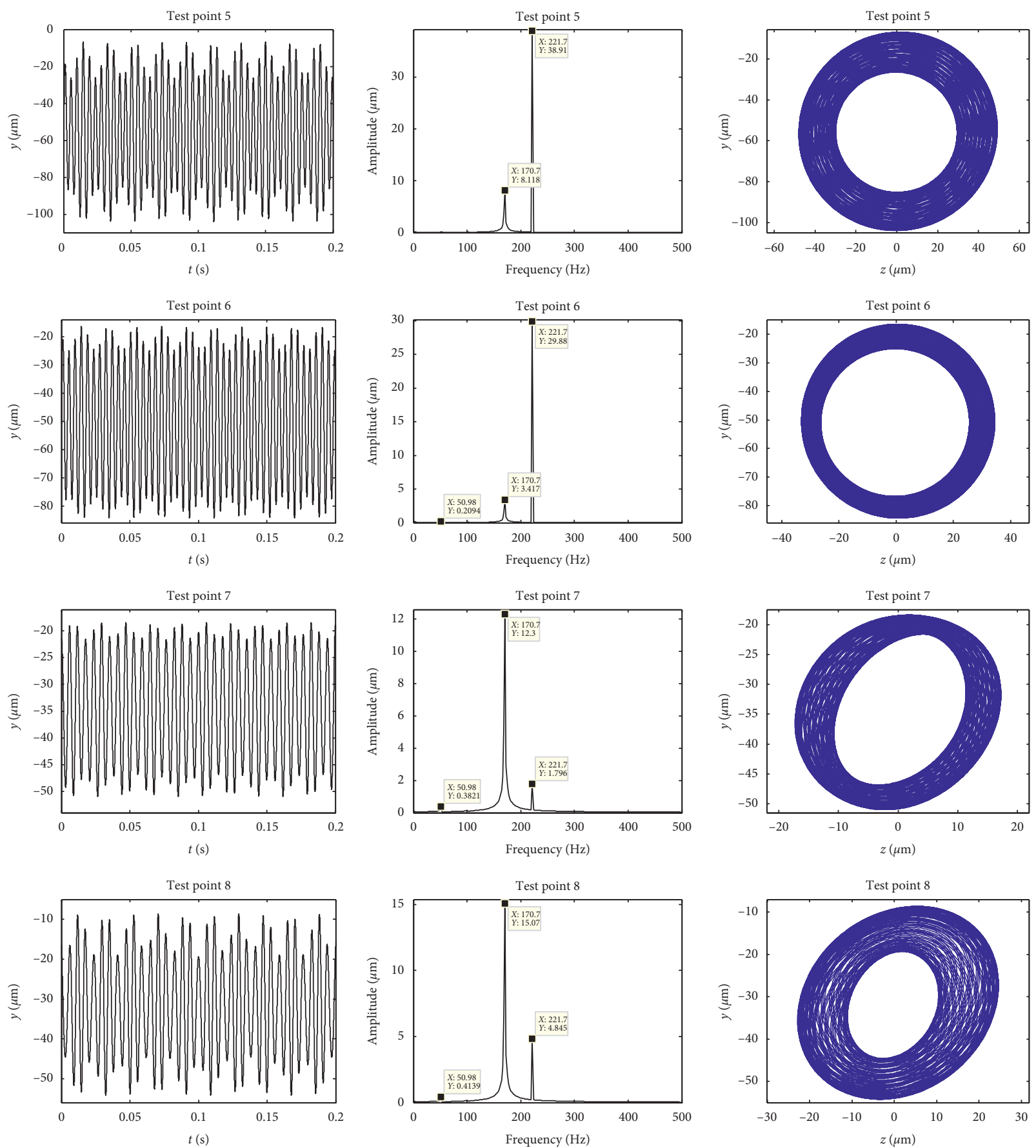

(b)

Figure 6: The time-domain diagram, spectrum, and axle center obit of the test point under the Case I.

Under the condition of no rub-impact and three different rub-impact degrees, the amplitude of speed frequency in each measuring point of the dual-rotor system is compared and analyzed, as shown in Figure 10. It can be seen that the vibration amplitude of every test point with the rubimpact fault is greater than that with an unbalanced condition, and with the increase of the rub-impact degree, the vibration amplitude of each measuring point increases. The
No. 5 (4\# fulcrum) and No. 6 (HPC) measuring points on the high-pressure rotor are the least affected by the highpressure turbine disc rub-impact and are mainly affected by the high-pressure compressor disc unbalance. Especially, the position of the No. 6 measuring point is the unbalanced position of the high-pressure rotor, and its axis orbit is relatively regular. Compared with Figures $10(a)$ and 10 (b), it can be seen that the vibration of the low-pressure turbine 

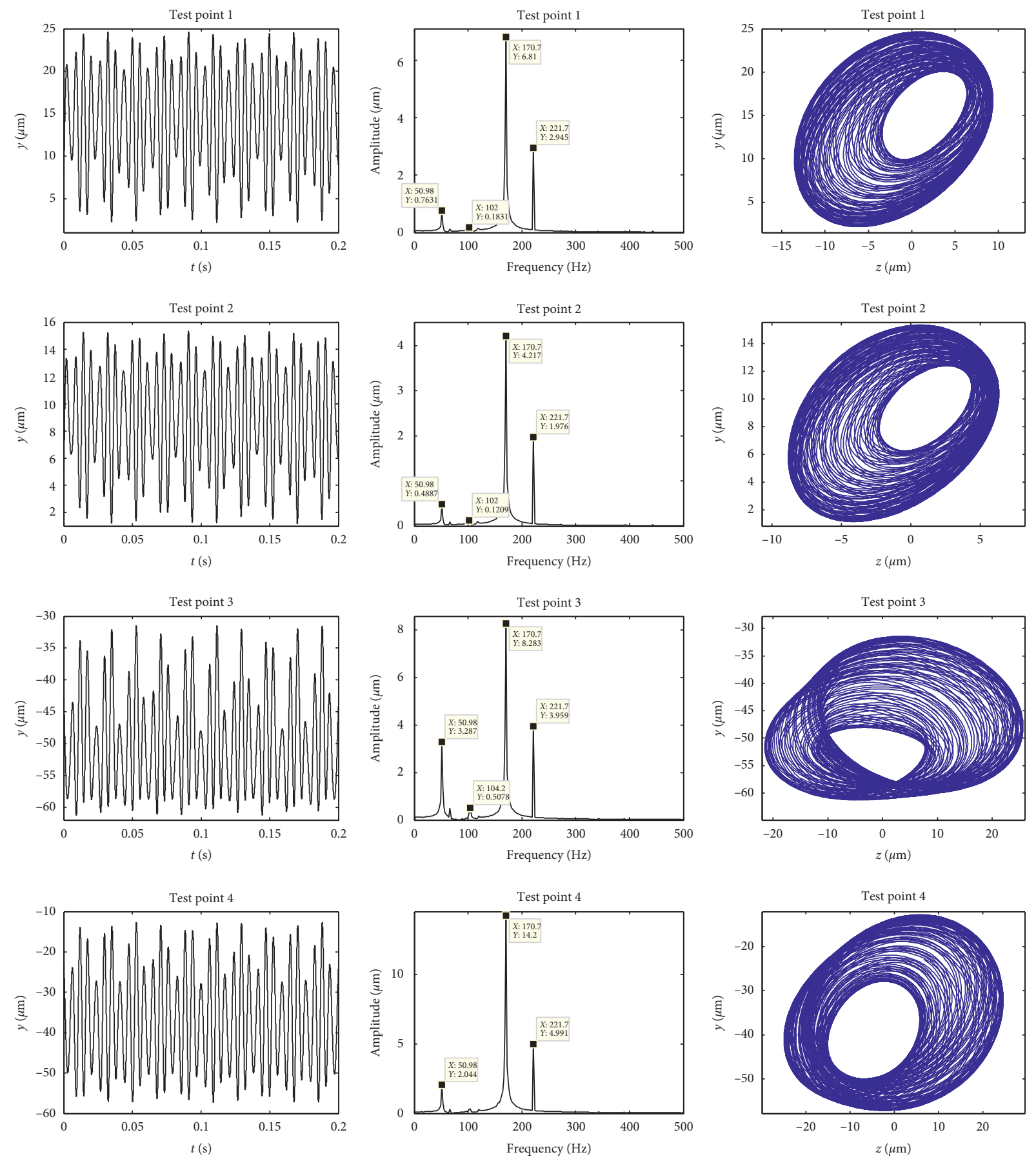

(a)

Figure 7: Continued. 

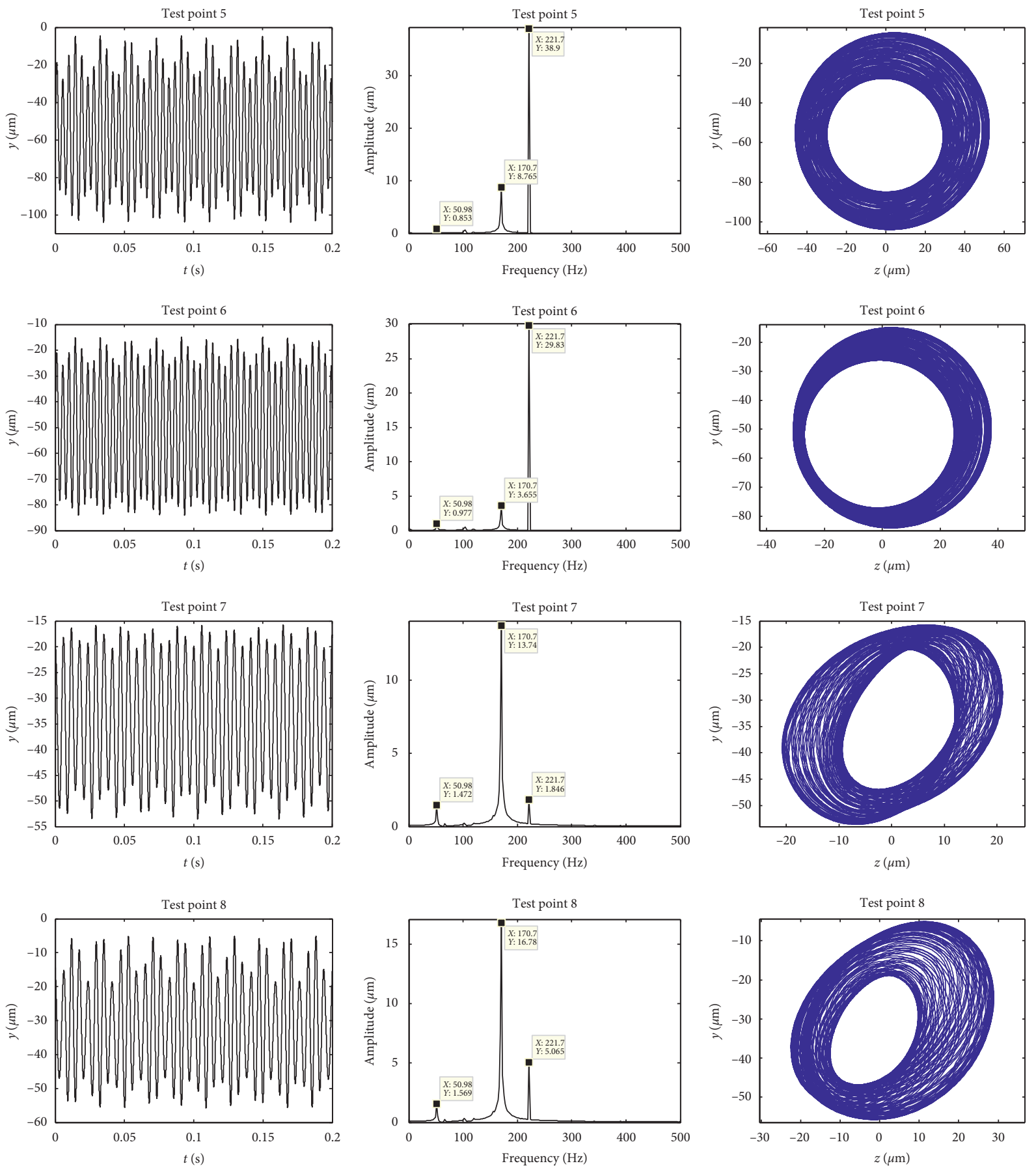

(b)

Figure 7: The time-domain diagram, spectrum, and axle center obit of the test point under Case II.

disc position is least affected by the high-pressure turbine disc rubbing. The transfer law of speed frequency of the dualrotor vibration on high- and low-pressure rotors remains unchanged. The vibration magnitude ordering of $N 1$ was $8>4>7>3>5>1>2>6$, and that of $N 2$ was $5>6>4>8>3>1>2>7$.

7.2.2. Influence of Rub-Impact Parameters on the Vibration Response of the Dual-Rotor System. Rub-impact stiffness, rub-impact clearance, and friction coefficient are three important parameters in the rub-impact fault model. In this section, the influence of the three typical rub-impact parameters on the vibration response of the dual-rotor system is studied with three cases shown in Table 6 . The vibration amplitude of fundamental frequency (N1 and N2) and 2 times of the high-pressure rotational frequency (2N2) are obtained in three cases. The influence of different rub-impact stiffness, rub-impact clearances, and rub-impact friction coefficients is compared. The representative results are shown in Figures 11-13 which 

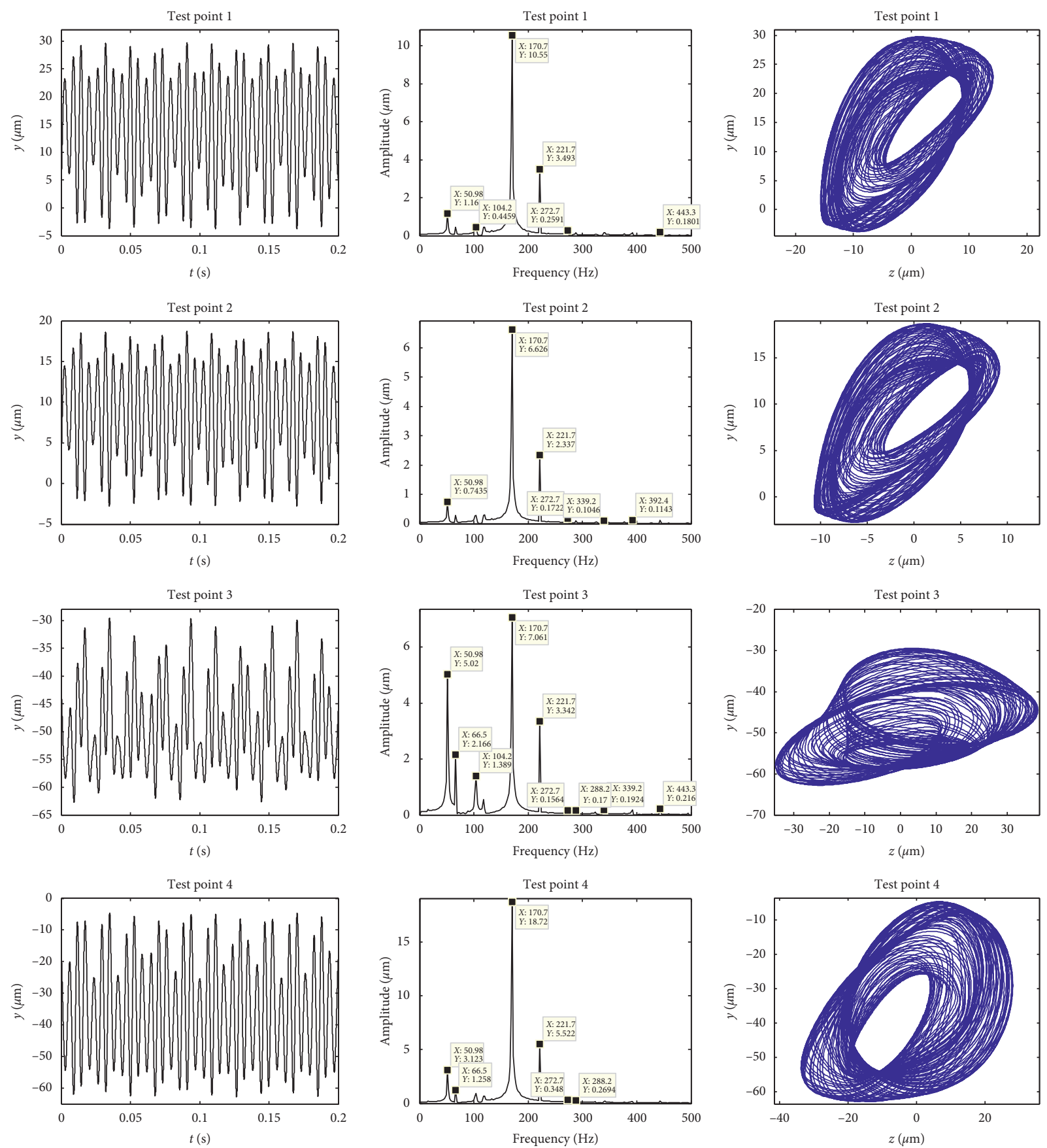

(a)

FIgURE 8: Continued. 

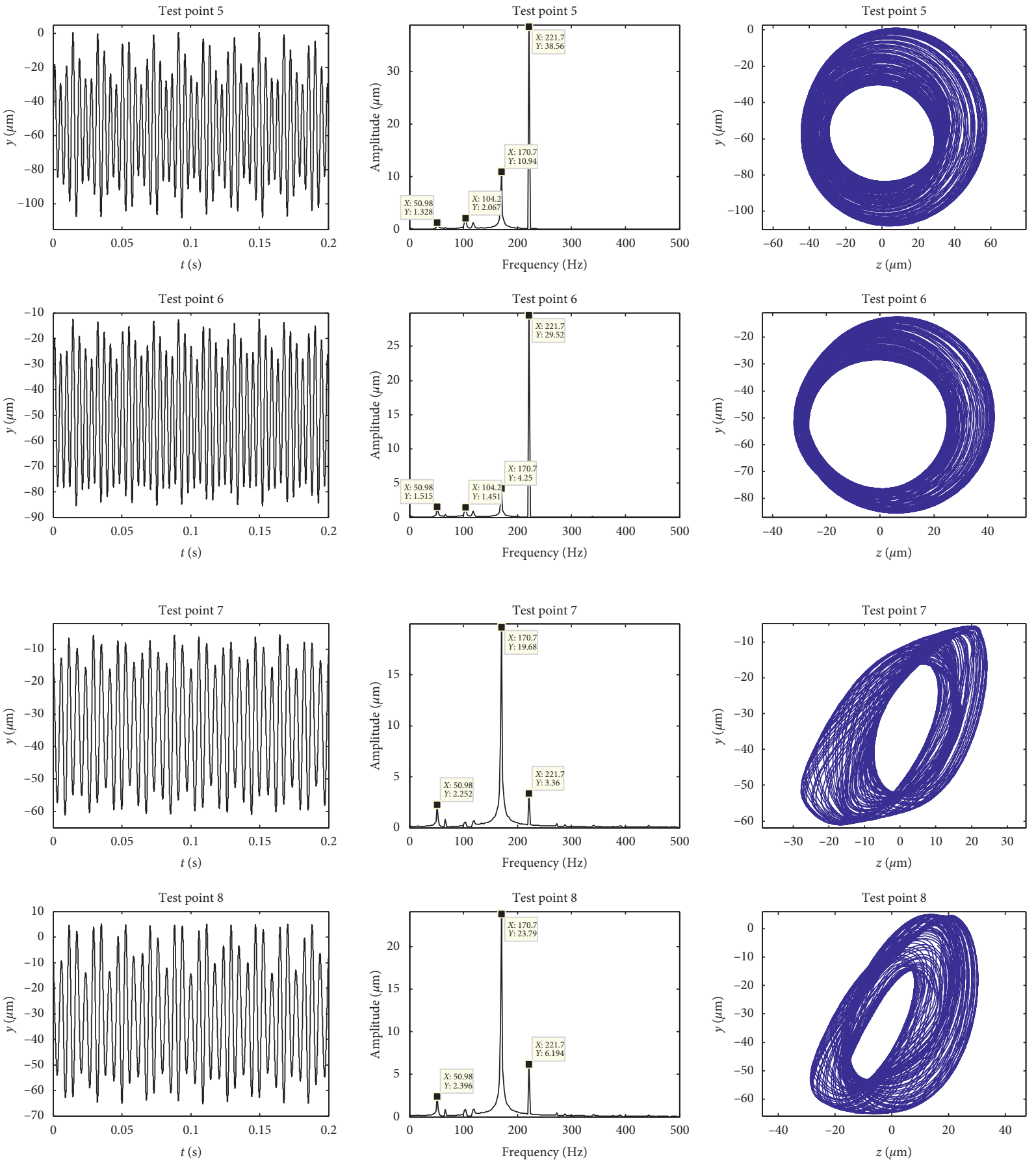

(b)

FIgURE 8: The time-domain diagram, spectrum, and axle center obit of the test point under Case III.

are the amplitudes of $N 1, N 2$, and $2 N 2$ of each measuring point with the change of the rub-impact parameters.

From Figure 11, we can see that under the three different parameter settings, the vibration amplitude of $N 1$ at each measuring point has a small change, among which the variation of measuring points 2 and 6 is the smallest.

From Figure 12, we can see that under the three different parameter settings, the vibration amplitude of $\mathrm{N}_{2}$ at each measuring point changes little, among which the variation of measuring points 5 and 6 of the high-pressure rotor is the largest.

It can be seen from Figure 13 that the amplitude of $2 \mathrm{~N} 2$ at each measuring point changes slightly under the setting of I and III rubbing parameters, while the amplitude of $2 \mathrm{~N} 2$ at each measuring point increases under the setting of the rubbing parameter in case II.

From Figures 11-13, it can be seen that the amplitude changes of $N 1$ and $N 2$ are less affected by friction coefficient 


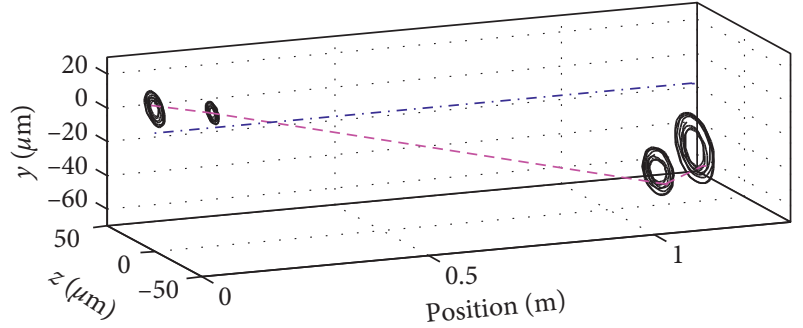

(a)

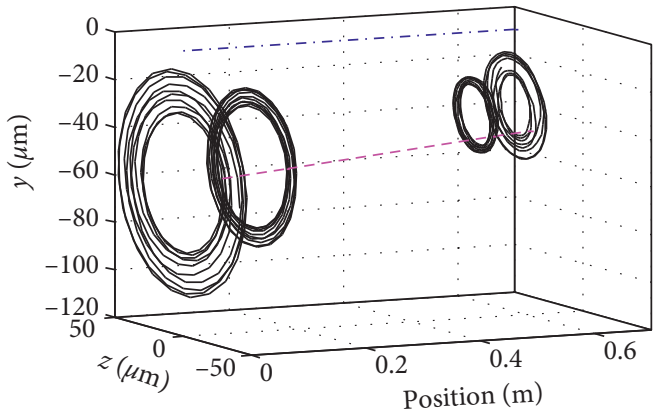

(b)

FiguRE 9: Axis orbit diagram of the high- and low-pressure rotors. (a) The low-pressure rotor axis orbit diagram. (b) The high-pressure rotor axis orbit diagram.

and rub-impact clearance and mainly affected by the unbalance of high and low rotors. The influence of friction coefficient on the amplitude of $2 N 2$ is greater than that of rub-impact clearance.

Among the three rub-impact parameters, the rub-impact stiffness has the greatest influence on the vibration response of each measuring point of the dual-rotor system, while the friction coefficient and rub-impact clearance have little influence on the vibration response of each measuring point of the dual-rotor system.

\subsection{Influence of Rotating Speed on the Vibration Response} of the Dual-Rotor System. To study the influence of rotating speed on the vibration of the dual-rotor system under the rub-impact fault, in this section, without changing the unbalance of the rotor system, the vibration response of the dual-rotor system with the low-pressure speed $N 1=50 \mathrm{~Hz}$, high-pressure speed $N 2=60 \mathrm{~Hz}$, and rubimpact stiffness $7 \times 10^{6} \mathrm{~N} / \mathrm{m}$ is studied. The vibration time domain and frequency spectrum axis trajectory of each measuring point are obtained, as shown in Figure 13.

In view of the influence of rotating speed on the vibration characteristics of the double-rotor system under the rub-impact fault, the vibration response of the double-rotor system with low-pressure speed, highpressure speed $\mathrm{N} 2=60 \mathrm{~Hz}$, and rub-impact stiffness $7 \times 10^{6} \mathrm{~N} / \mathrm{m}$ is studied without changing the rotor system unbalance. The vibration time domain and frequency spectrum of each measuring point are obtained, as shown in Figure 14.

By comparing the results of Figure 14 with Figure 8, it is found that the vibration response characteristics of the dualrotor system caused by the rub-impact fault are not completely identical at two speeds. The frequency components $N 1, N 2$, and N2-N1 appear in the vibration spectrum in both speed conditions. In Figure 13, in addition to the above frequency components, there are $2 N 2-N 1,2 N 2$, and $3 N 2$ in the spectrum of each measuring point. Under the case of rotating speed $N 1=50 \mathrm{~Hz}$ and $N 2=60 \mathrm{~Hz}$, high-voltage frequency conversion $N 2$ is dominant in the vibration spectrum of each measuring point, and there is no obvious peak in the time-domain diagram. The orbit of the shaft center is enveloped ellipse shape, which is more regular than the results in Figure 8.

\section{Simulation Verification}

8.1. Establishment of a Rigid-Flexible Coupling Multibody Dynamic Model for the Dual-Rotor System. ADAMS (automatic dynamic analysis of mechanical systems) is a professional product with rich industry application experience. It is the only dynamic simulation software verified by a large number of practical projects [23-28]. The dynamic modeling, analysis, and vibration prediction of the aeroengine rotor system based on rigid-flexible coupling multibody dynamic system simulation technology can meet the requirements of characteristics' analysis of the hierarchical system and rigid-flexible coupling structure and vibration prediction of the rotor system in the process of new rotor design. In particular, the simulation analysis of typical vibration problems such as unbalance and rub-impact of the rotor system can be realized effectively.

The 'impact' is used to calculate the rub-impact force in ADAMS, which is based on the impact function to calculate the contact force between the two objects. The contact force is composed of two parts: the first part is the elastic force due to the mutual penetration between the two objects, and the other part is the damping force produced by relative speed.

The rub-impact mechanics expression is

$$
F=\left\{\begin{array}{l}
0, \quad x \geq \delta_{0} \\
k\left(\delta_{0}-x\right)^{e}-N C_{\max } \operatorname{step}\left(x, \delta_{0}-d, 1, \delta_{0}, 0\right) \quad x \ll \delta_{0}
\end{array}\right.
$$

Among them, $k$ is the stiffness coefficient, $\delta_{0}$ is the initial distance between the two contact objects, $x$ is the actual distance between the two contact objects in the rubbing process, $C_{\max }$ is the maximum damping coefficient used to characterize the collision energy loss, $N$ is the rotating shaft speed (high- and low-pressure rotor speeds are $N 2$ and $N 1$, respectively), $e$ is the rub-impact index used to represent the nonlinear degree of the material, and $\mathrm{d}$ is the penetration depth. 


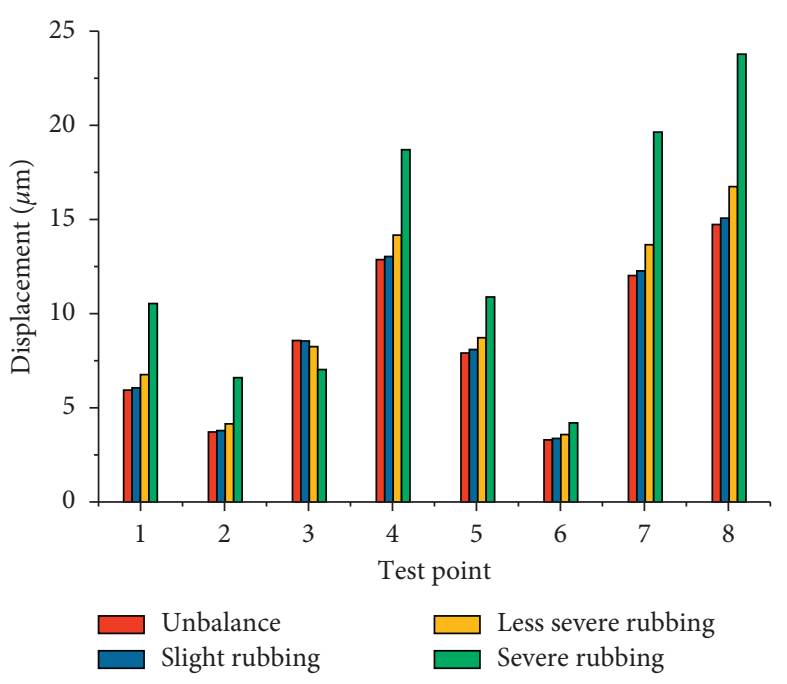

(a)

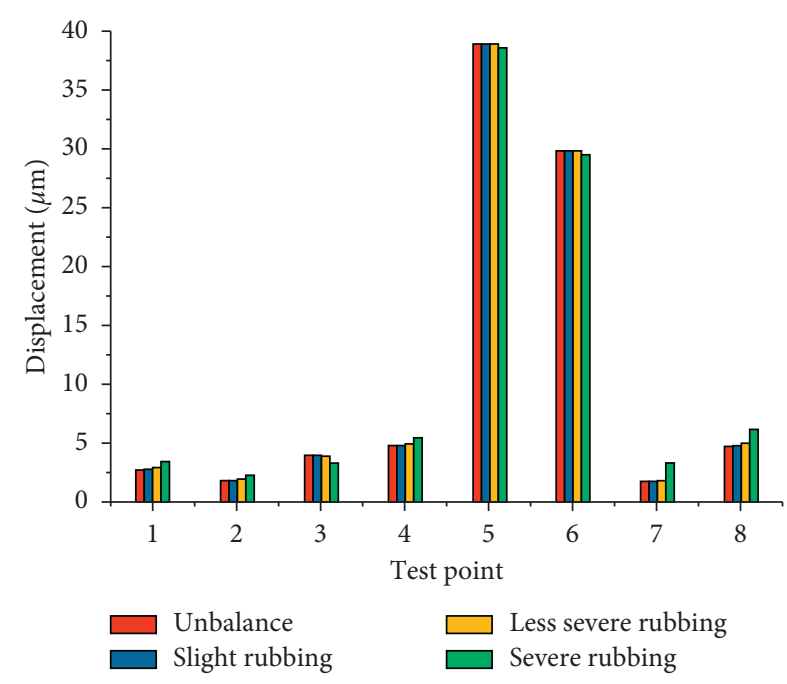

(b)

Figure 10: The amplitude of vibration frequencies $N 1$ and $N 2$ at each measuring point of the dual rotor is affected by rub-impact. (a) N1. (b) N2.

TABle 6: Parameter setting of the rub-impact model.

\begin{tabular}{lccc}
\hline Parameter & $\mathrm{I}$ & $\mathrm{II}$ & \\
\hline Rub-impact stiffness & $3 \times 10^{6} \mathrm{~N} / \mathrm{m}$ & $3 \times 10^{6} \mathrm{~N} / \mathrm{m}$ & III \\
Friction coefficient & 0.4 & 0.4 & $3 \times 10^{6} \mathrm{~N} / \mathrm{m}$ \\
Rubbing clearance & $1 \times 10^{-7} \mathrm{~m}$ & $1 \times 10^{-6} \mathrm{~m}$ & 0.6 \\
LPC unbalance1 & $500 \mathrm{~g} \mathrm{~mm}$ & $500 \mathrm{~g} \mathrm{~mm}$ & $1 \times 10^{-7} \mathrm{~m}$ \\
HPC unbalance & $500 \mathrm{~g} \mathrm{~mm}$ & $500 \mathrm{~g} \mathrm{~mm}$ & $500 \mathrm{~g} \mathrm{~mm}$ \\
\hline
\end{tabular}

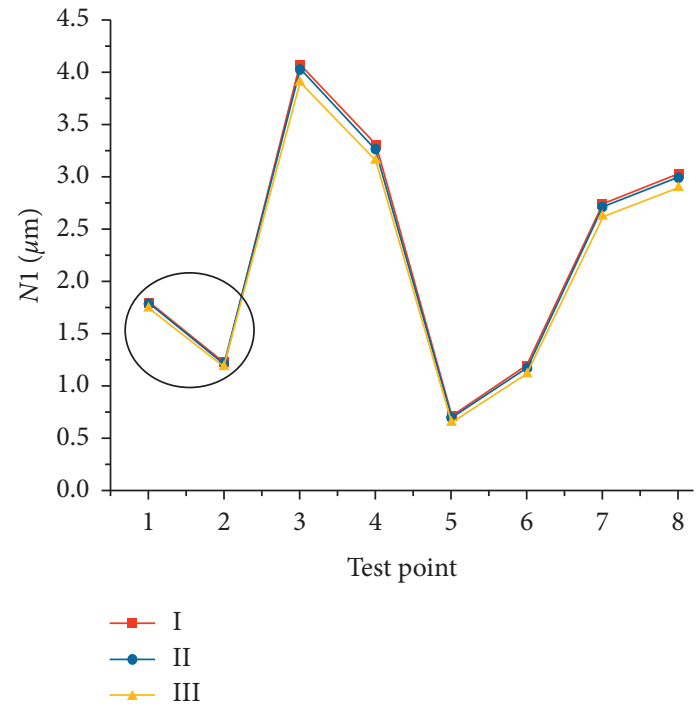

(a)

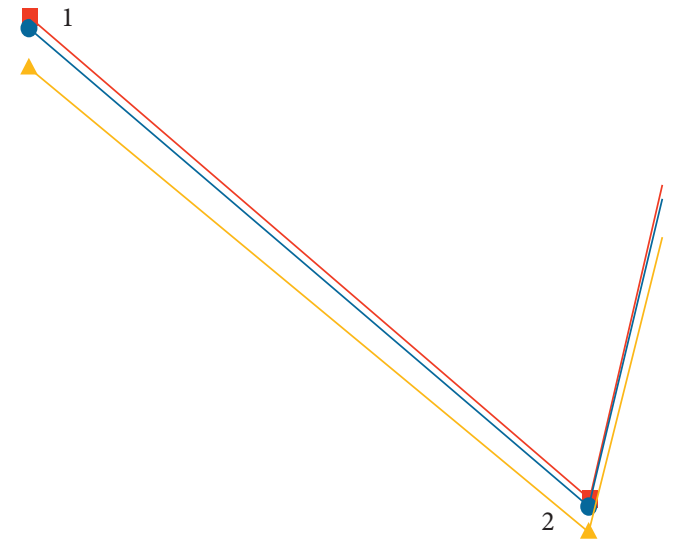

(b)

FIGURE 11: The vibration amplitude of $N 1$ with different rub-impact parameters.

The low-pressure turbine shaft is considered as a flexible shaft, and the elastic support is simulated by a squirrel-cage elastic structure, and other parts are assumed to be rigid. When modeling the dual-rotor system, in order to truly reflect the connection state between various parts of the model, the parts originally fixed by bolts are connected with fixed pairs. The bearing is defined by stiffness and damping, simulated by the "bushing" element, and the coupling is 


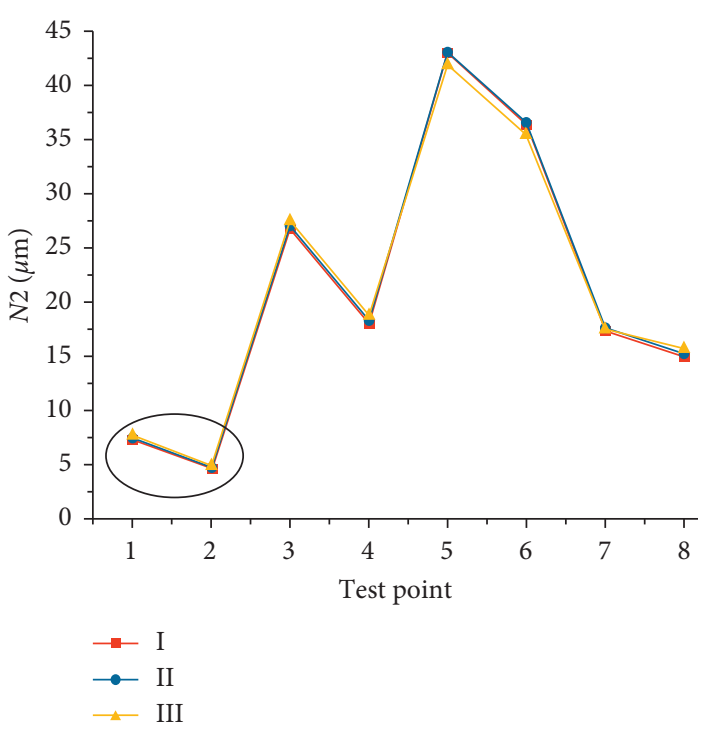

(a)

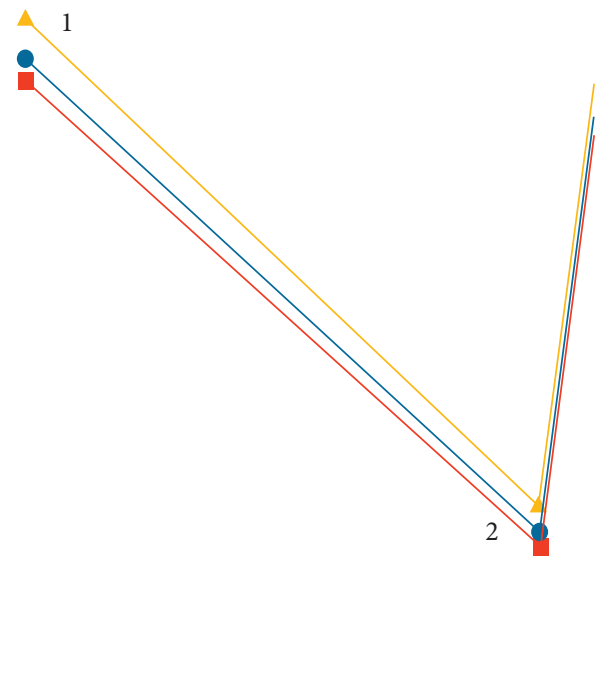

(b)

FIgURE 12: The vibration amplitude of $N 2$ with different rub-impact parameters.

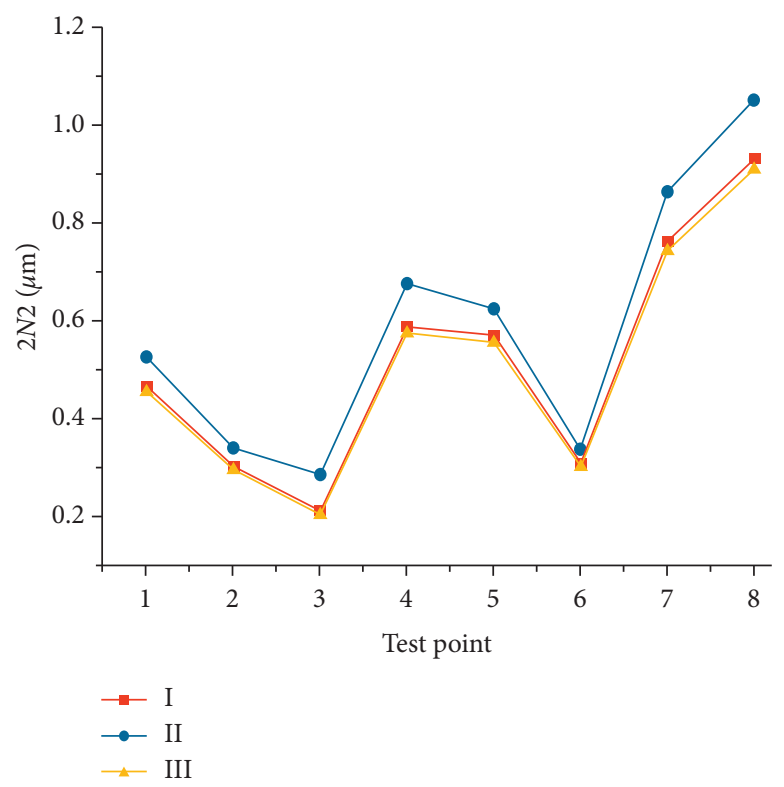

FiguRE 13: The vibration amplitude of $2 N 2$ with different rub-impact parameters.

simplified as a short shaft structure. In order to ensure the steady increase of the speed, the step function is usually used to set the speed.

The dual-rotor system unbalance is simulated by adding a mass block on the low-pressure compressor disc and the high-pressure compressor disc. A rub-impact block is set at a certain clearance from the high-pressure turbine disc (HPT). The fixed pair is used to define the rub-impact block as the stator. The contact adjustment clearance and rubbing parameters are set between the high-pressure turbine disc and the rubbing block to simulate different rubbing conditions. Finally, the rigid-flexible coupling multibody dynamic model of the dual-rotor system with rub-impact is shown in
Figure 15. Low-pressure speed $N 1=50 \mathrm{~Hz}$ and high-pressure speed $N 2=60 \mathrm{~Hz}$. The rigid-flexible coupling simulation model of the dual-rotor system is shown in Figure 15.

To verify the correctness of the model and the simulation accuracy, the first two natural frequencies of the dual-rotor system are obtained by ADAMS in Figure 16. And the results are compared with the analytical results based on the dynamic equation. The results show that the first two modes are consistent. The first and second modes of the lowpressure rotor are mainly the first-order bending of the lowpressure turbine shaft. The first mode of the high-pressure rotor is translational, and the second is the pitching mode. The first natural frequency difference ratio is $5 \%$, and the 

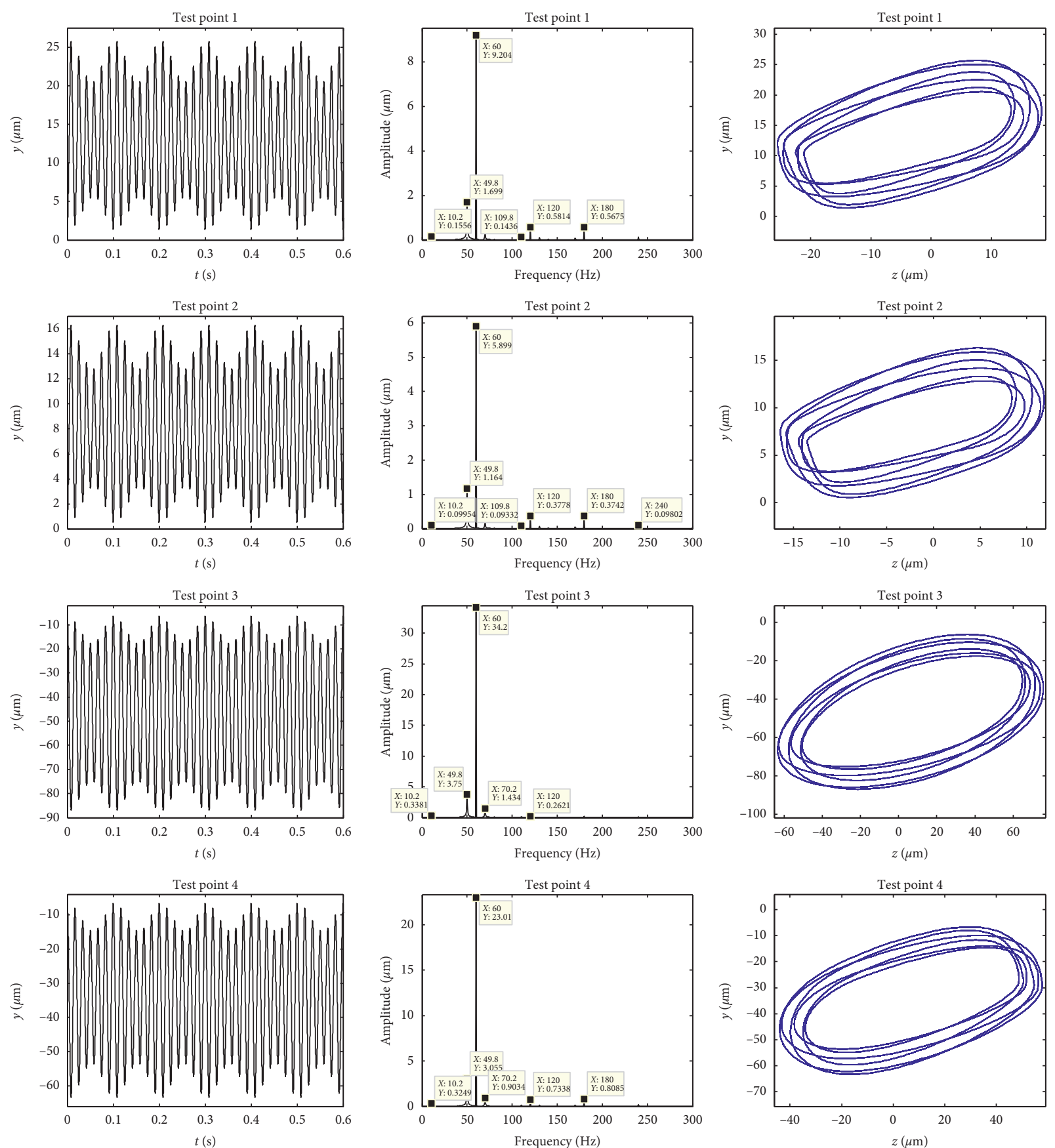

(a)

Figure 14: Continued. 

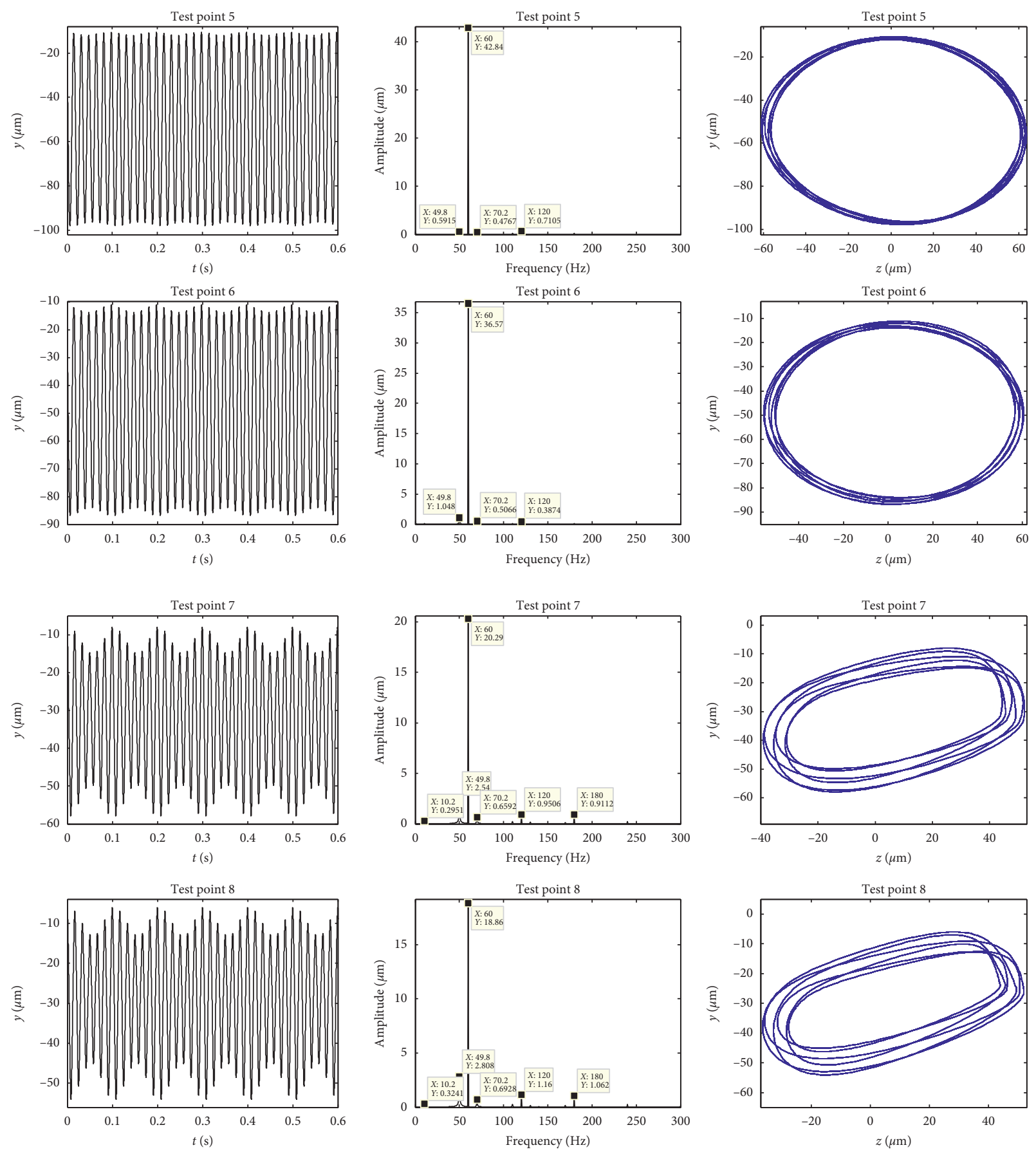

(b)

FIgURE 14: The time-domain diagram, spectrum, and axle center orbit of the dual-rotor system.

second natural frequency difference ratio is $4.5 \%$. The rationality of the simulation model is verified.

8.2. Parameter Setting of the Simulation. Based on the multibody dynamics model of the dual-rotor system with the rub-impact fault in Figure 15, the vibration response of the dual-rotor system is simulated with five different rub-impact states as shown in Table 7.

\subsection{Simulation Results}

8.3.1. Influence of Different Rubbing Stiffness on the Vibration. As shown in Table 4, the vibration of the dualrotor system under three different impact stiffness (1-3) is simulated and analyzed, and the vibration time domain, frequency spectrum, and high- and low-pressure rotor center orbit of each measuring point under three conditions are obtained, as shown in Figures 17-19. 


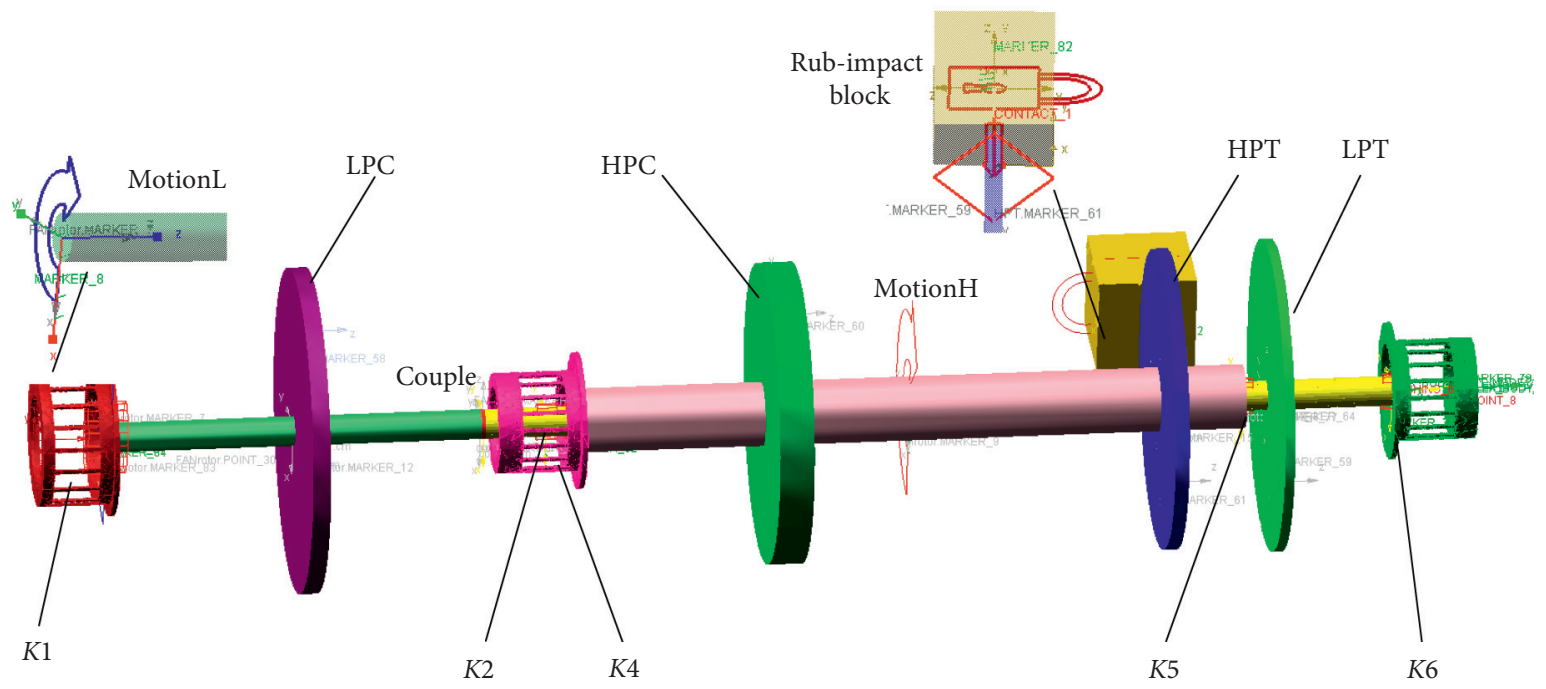

FIgURE 15: The multibody dynamic model of the dual-rotor system based on ADAMS.

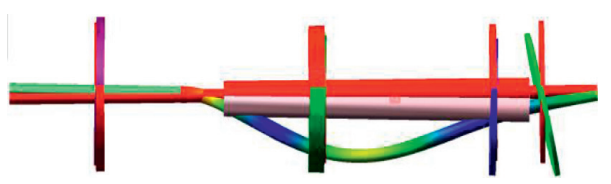

(a)

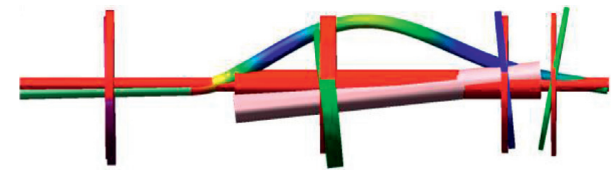

(b)

Figure 16: The first two modes and natural frequencies of the dual-rotor system based on ADAMS. (a) The first mode shape (53 Hz). (b) The second mode shape $(79 \mathrm{~Hz})$.

TABle 7: Parameter setting of the simulation model based on ADAMS.

\begin{tabular}{|c|c|c|c|c|c|}
\hline Parameter & Case 1 & Case 2 & Case 3 & Case 4 & Case 5 \\
\hline Rub-impact stiffness & $1 \times 10^{6} \mathrm{~N} / \mathrm{m}$ & $1 \times 10^{7} \mathrm{~N} / \mathrm{m}$ & $1 \times 10^{8} \mathrm{~N} / \mathrm{m}$ & $1 \times 10^{7} \mathrm{~N} / \mathrm{m}$ & $1 \times 10^{7} \mathrm{~N} / \mathrm{m}$ \\
\hline Rub-impact damping & $100 \mathrm{Ns} / \mathrm{m}$ & $1000 \mathrm{Ns} / \mathrm{m}$ & $10000 \mathrm{Ns} / \mathrm{m}$ & $1000 \mathrm{Ns} / \mathrm{m}$ & $1000 \mathrm{Ns} / \mathrm{m}$ \\
\hline Force exponent & 1.5 & 1.5 & 1.5 & 1.5 & 1.5 \\
\hline Penetration depth & $0.1 \mathrm{~mm}$ & $0.1 \mathrm{~mm}$ & $0.1 \mathrm{~mm}$ & $0.1 \mathrm{~mm}$ & $0.1 \mathrm{~mm}$ \\
\hline Rubbing clearance & $1 \times 10^{-7} \mathrm{~m}$ & $1 \times 10^{-7} \mathrm{~m}$ & $1 \times 10^{-6} \mathrm{~m}$ & $1 \times 10^{-7} \mathrm{~m}$ & $1 \times 10^{-7} \mathrm{~m}$ \\
\hline LPC unbalance & $500 \mathrm{~g} \mathrm{~mm}$ & $500 \mathrm{~g} \mathrm{~mm}$ & $500 \mathrm{~g} \mathrm{~mm}$ & $1000 \mathrm{~g} \mathrm{~mm}$ & $500 \mathrm{~g} \mathrm{~mm}$ \\
\hline HPC unbalance & $500 \mathrm{~g} \mathrm{~mm}$ & $500 \mathrm{~g} \mathrm{~mm}$ & $500 \mathrm{~g} \mathrm{~mm}$ & $500 \mathrm{~g} \mathrm{~mm}$ & $1000 \mathrm{~g} \mathrm{~mm}$ \\
\hline
\end{tabular}

Analyzing the results shown in Figures 17-19, through the vibration time-domain diagram of each measuring point of the dual-rotor system, it is found that, with the increase of the rub-impact stiffness, the vibration amplitude of each measuring point increases. Through the frequency spectrum, it can be seen that, with the increase of the rub-impact stiffness, the vibration spectrum components of each measuring point become more complex, and there are multiple combination and division frequency components, such as $(2 N 2-N 1) / 2,2 N 2-N 1$, $(4 N 1+N 2) / 2$, and $(2 N / 1-N 2) / 2$, and $N 2$ and $2 N 1-N 2$ are the main frequencies. Through the analysis of the axis trajectory diagram, it is found that, as the degree of rubimpact increases, the axis trajectory of each measuring point becomes messy, no longer a regular circle or ellipse, and sharp corners appear in the rubbing direction. The simulation results are consistent with the theoretical analysis results.

\subsubsection{Influence of Unbalance of the Dual-Rotor System on the} Rub-Impact Vibration. The rub-impact vibration characteristics of the dual-rotor system with 4 and 5 parameters in Table 4 are analyzed, and the influence of unbalance on the rub-impact vibration is studied. The vibration response of the dual-rotor system is obtained, as shown in Figures 20 and 21 , respectively.

Comparing Figure 20 with Figure 21, it can be found that the influence of the fan disc unbalance on the rub-impact response of the dual-rotor system is greater than that of the high-pressure compressor disc unbalance. The increase of fan disc unbalance has a great influence on the vibration 

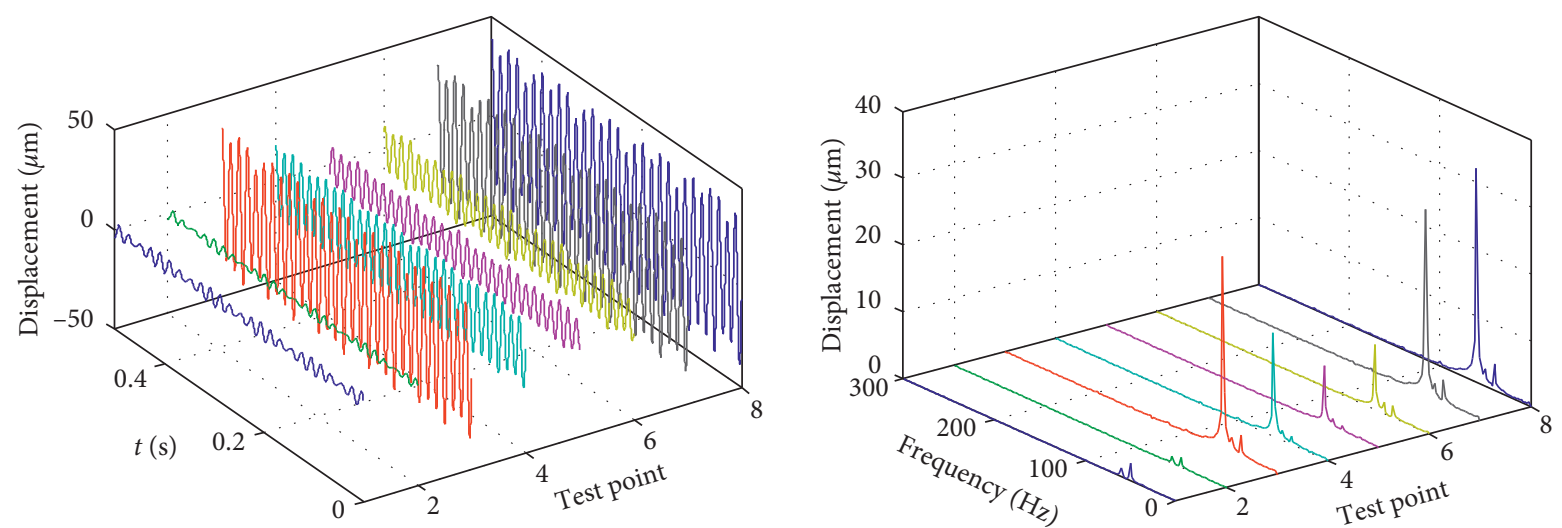

(a)

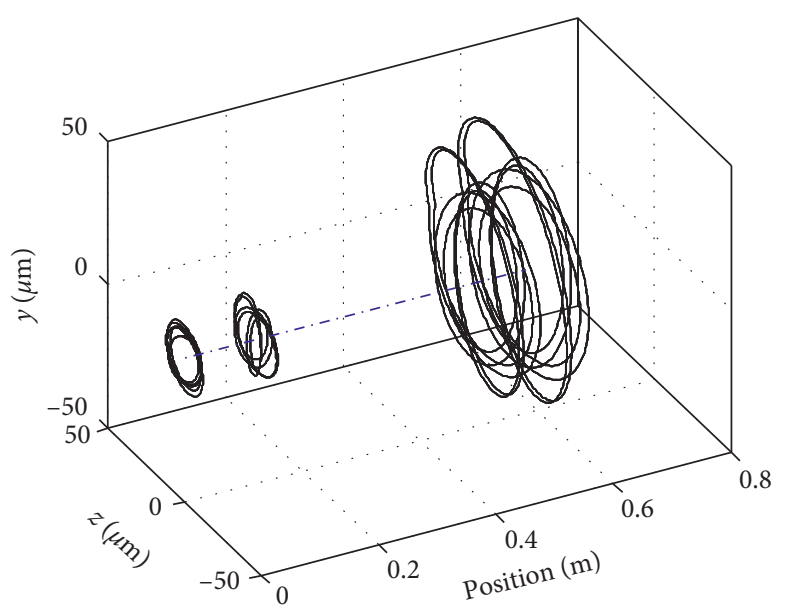

(b)

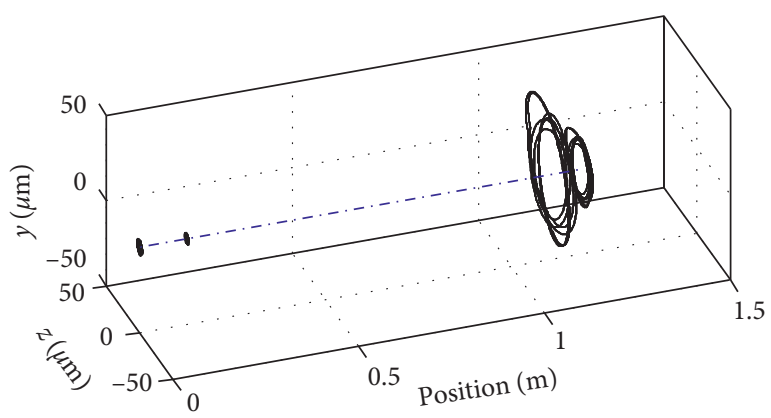

(c)

(d)

FIgURE 17: The vibration of the dual-rotor system with slight rubbing (case 1). (a) Time-domain diagram of each measuring point. (b) Spectrum of each measuring point. (c) Axis orbit of the low-pressure rotor. (d) Axis orbit of the high-pressure rotor.

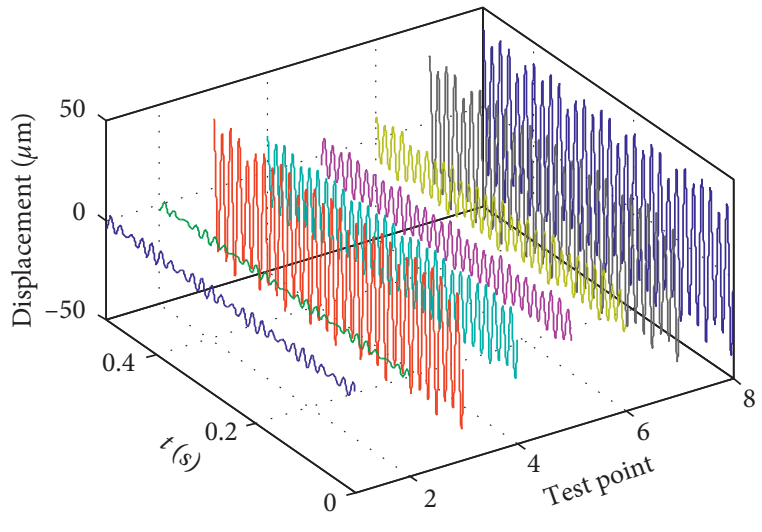

(a)

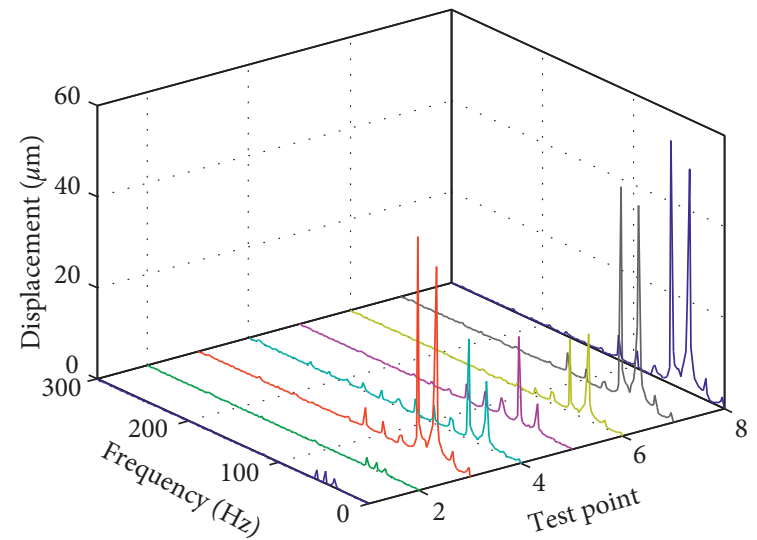

(b)

FIGURE 18: Continued. 


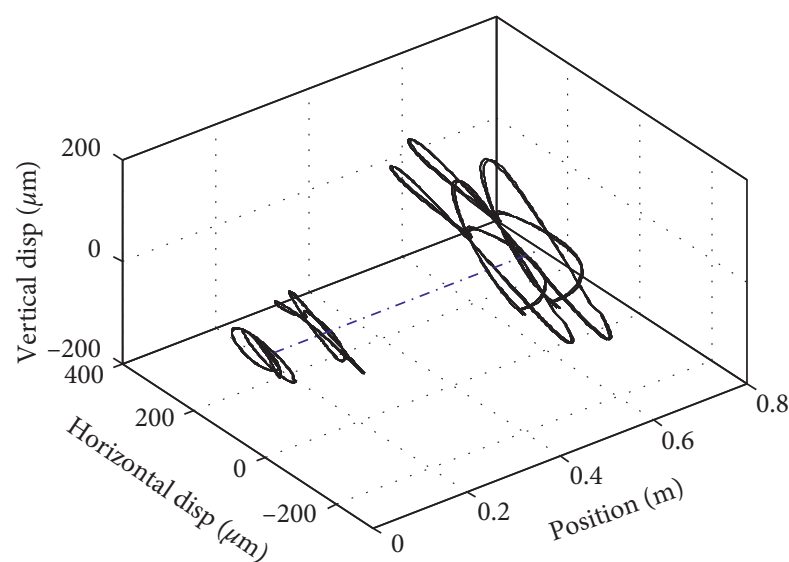

(c)

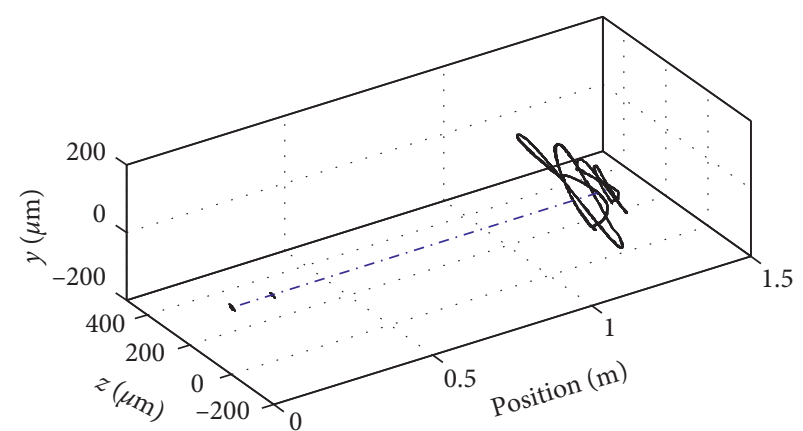

(d)

Figure 18: The vibration of the dual-rotor system with less severe rubbing (case 2). (a) Time-domain diagram of each measuring point. (b) Spectrum of each measuring point. (c) Axis orbit of the low-pressure rotor. (d) Axis orbit of the high-pressure rotor.

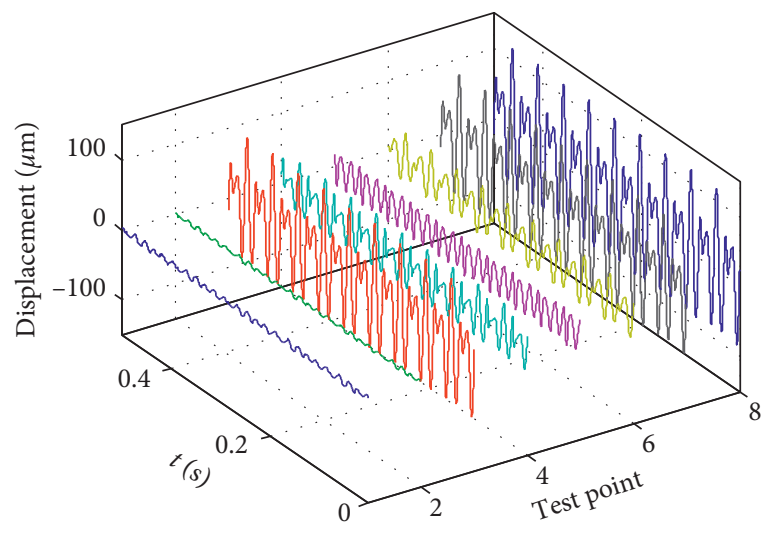

(a)

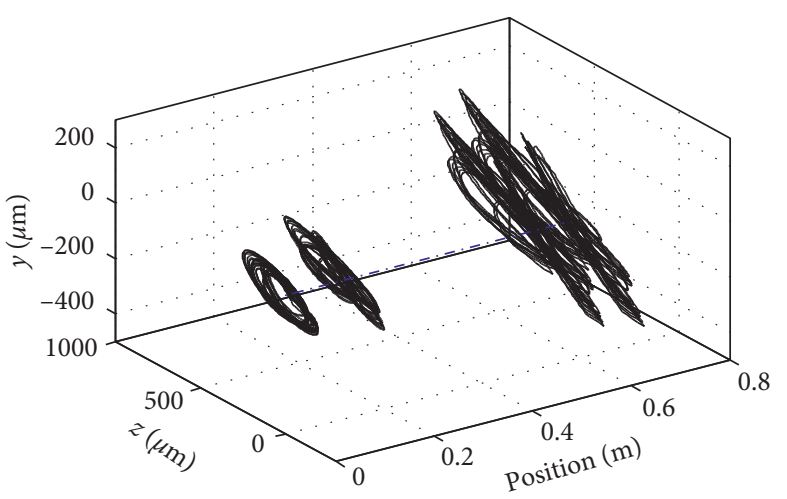

(c)

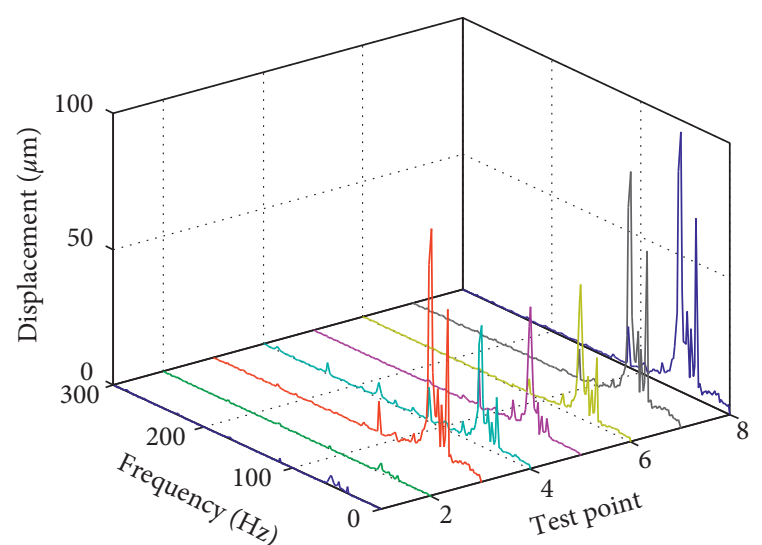

(b)

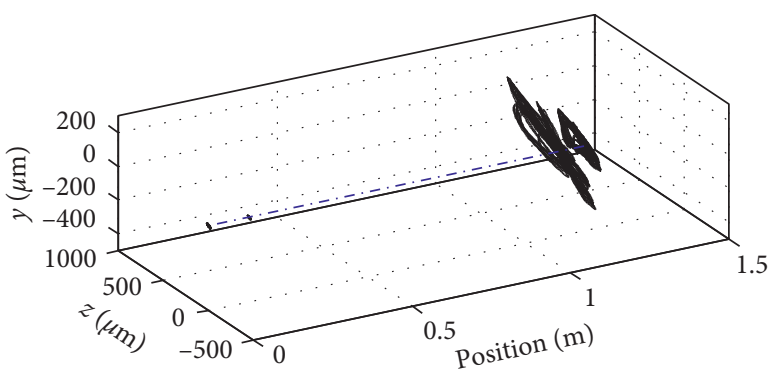

(d)

FiguRE 19: The vibration of the dual-rotor system with severe rubbing (case 3). (a) Time-domain diagram of each measuring point. (b) Spectrum of each measuring point. (c) Axis orbit of the low-pressure rotor. (d) Axis orbit of the high-pressure rotor.

response of the low-pressure rotor, but has little influence on the vibration response of the high-pressure rotor.

The amplitude of frequency $N 2$ in the spectrum of each measuring point of the low-pressure rotor increases with the increase of unbalance, and the impact of LPC unbalance is more obvious than that of HPC. It can be seen from the analysis that rotor unbalance will aggravate the vibration of the dual-rotor system caused by the rub-impact fault, and the rub-impact fault should be avoided as far as possible in design, assembly, and processing.

The application of simulation technology in the aviation field can improve the vibration prediction and analysis 

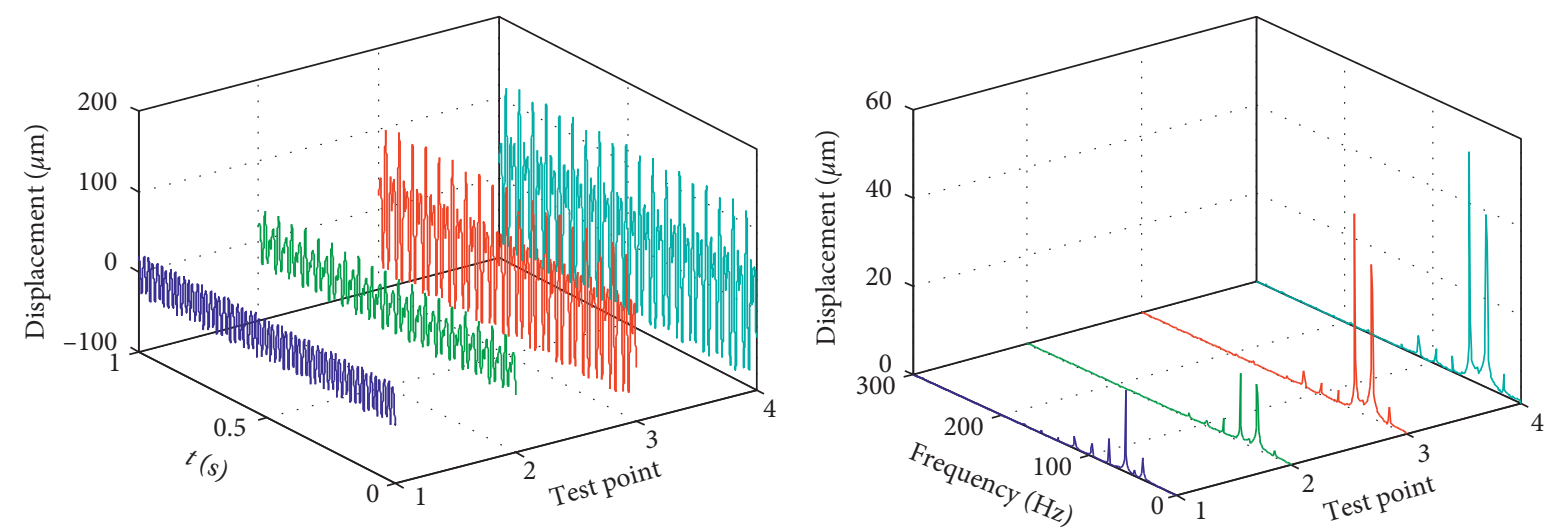

(a)

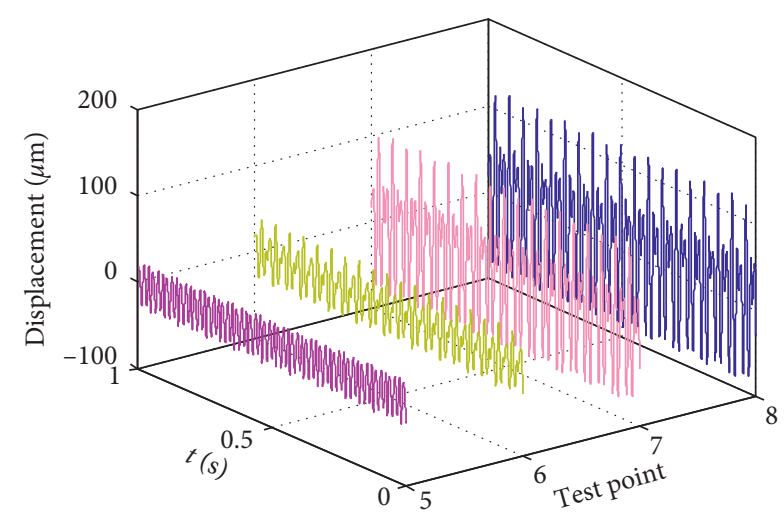

(c)

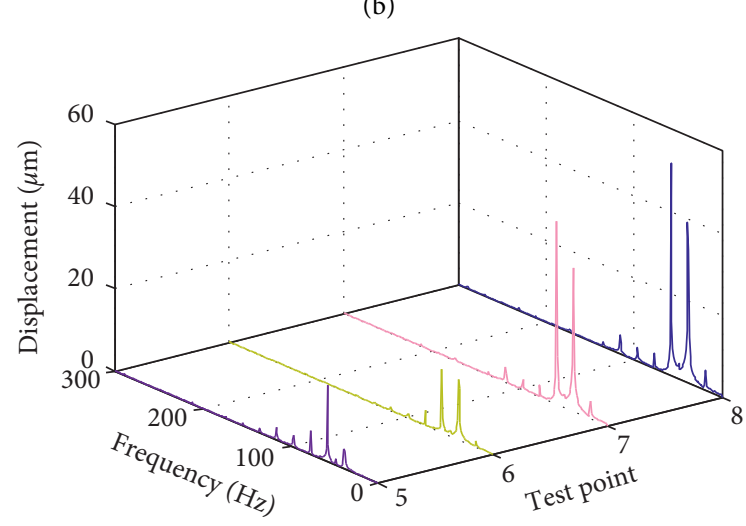

(d)

FIGURE 20: The influence of LPC unbalance on the vibration response of the dual-rotor system with the rub-impact fault (Case 4). (a) Timedomain and frequency spectrum of the low-pressure rotor at measuring points 1-4. (b) Time-domain and frequency spectrum of the highpressure rotor at measuring points $5-8$.

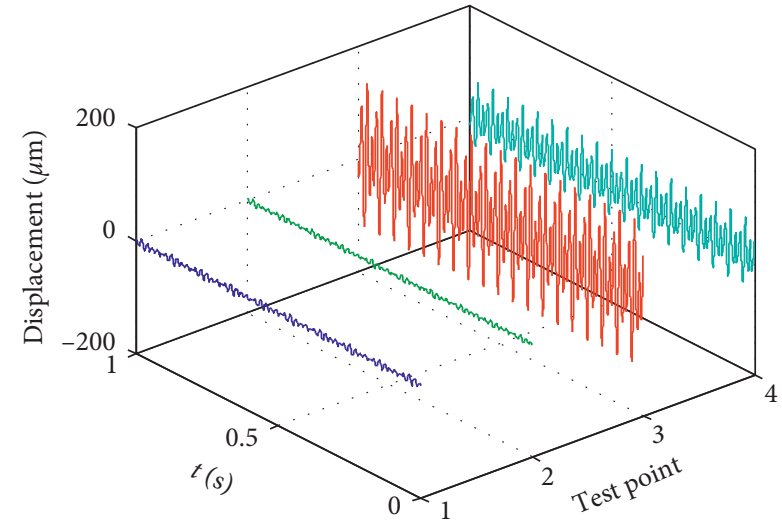

(a)

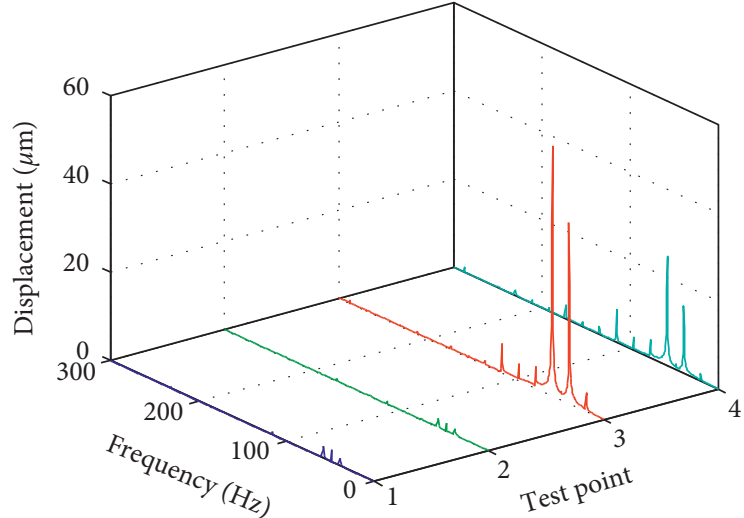

(b)

FIgure 21: Continued. 


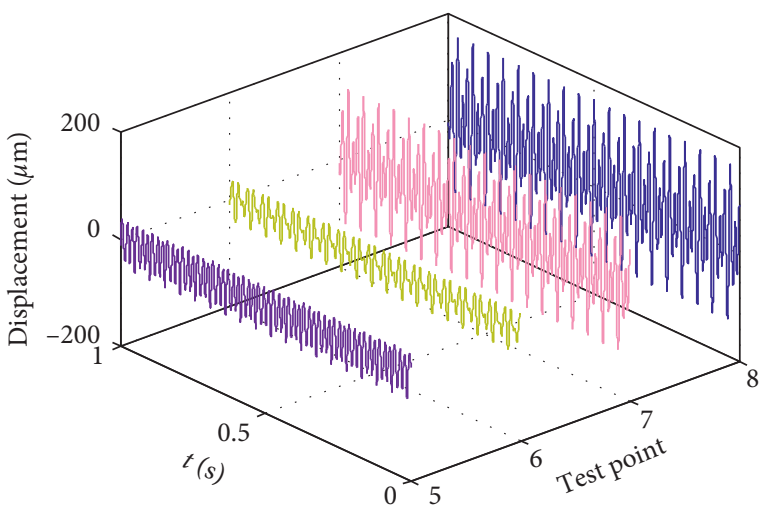

(c)

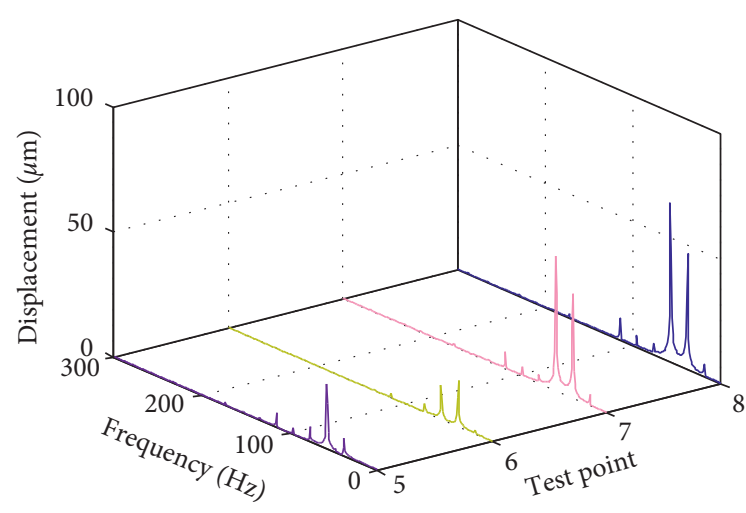

(d)

Figure 21: The influence of HPC unbalance on the vibration response of the dual-rotor system with the rub-impact fault (Case 5). (a) Timedomain and frequency spectrum of the low-pressure rotor at measuring points 1-4. (b) Time-domain and frequency spectrum of the highpressure rotor at measuring points $5-8$.

technology of a complex aeroengine rotor system. It can improve the stability and vibration control ability of the aeroengine rotor system, as well as the ability of dynamic analysis and design of the aeroengine rotor system.

Comparing the vibration response of the dual-rotor system under the rub-impact fault in this paper with the results in [29-32], it can be seen that the double frequency and combined frequency of the high- and low-pressure rotors appear in the rub-impact vibration response of the dual-rotor system, such as $2 N 2-N 1,2 N 1-N 2, N 2-N 1,2 N 1$, $2 N 2, N 1 N 2$, and N2-N1. Moreover, with the difference in rotational speed, rub-impact stiffness, and rub-impact position, the performance of each component is obviously different. In addition, the dual-rotor system model applied in this paper also has the frequency division N2/2 of the fundamental frequency and the frequency division components of the combined frequency, such as $(2 N 2-N 1) / 2$, $(2 N 1-N 2) / 2$, and $(4 N 1 N 2) / 2$.

\section{Conclusions}

The dynamic modeling, analysis, and vibration prediction of the aeroengine rotor system based on the rigid-flexible coupling multibody dynamic system technology can meet the requirements of characteristics' analysis of the hierarchical system and rigid-flexible coupling structure and vibration prediction of the rotor system in the process of new rotor design. In particular, the simulation analysis of typical vibration problems such as unbalance and rub-impact of the rotor system can be realized effectively. In this paper, the vibration of the dual rotor with the rub-impact fault is studied by using the method of analysis and multibody dynamics simulation verification, and conclusions are obtained as follows:

(1) The low-pressure rotor rotation frequency (N1) and the high-pressure rotor rotation frequency (N2) are the only frequencies of the unbalanced response of the dual-rotor system. The axis orbit of each measuring point is a regular circle.
(2) The rub-impact between the high-pressure turbine disc and the stator makes the vibration response of the dual-rotor system have nonlinear characteristics. The dynamic response of the rotor also contains the combined and division components of the speed frequency, and the occurrence of the rub-impact fault makes the axis track no longer a regular circle. The occurrence of the rub-impact fault increases the amplitude of the rotational frequency of the dualrotor system.

(3) With the increase of the rub-impact stiffness, the amplitude of the rub-impact spectrum components increases, and the component of the spectrum becomes more complex.

(4) The transfer law of rotational frequencies (N1 and N2) of the dual-rotor vibration on high- and lowpressure rotors remains unchanged.

(5) In the dual-rotor vibration caused by unbalance and rub-impact faults, the amplitude of $N 1$ decreases along the transmission paths of low-pressure rotor 43-1-2 and high-pressure rotor 8-7-5-6. The amplitude of $N 2$ decreases along the transmission paths of low-pressure rotor 4-3-1-2 and high-pressure rotor 5-6-8-7.

(6) The vibration response characteristics of the dualrotor system caused by the fault are not completely identical at two speeds. The frequency components $N 1, N 2$, and $N 2-N 1$ appear in the vibration spectrum in both speed conditions.

(7) Among the three parameters of the rub-impact fault, the stiffness has the greatest influence on the vibration response of each measuring point of the dual-rotor system, while the friction coefficient and clearance have little influence on the vibration response of each measuring point of the dual-rotor system.

(8) The influence of the fan disc unbalance on the rubimpact response of the dual-rotor system is greater 
than that of the high-pressure compressor disc unbalance. The increase of fan disc unbalance has a great influence on the vibration response of the lowpressure rotor, but has little influence on the vibration response of the high-pressure rotor. The No. 5 (4\# fulcrum) and No. 6 (HPC) measuring points on the high-pressure rotor are the least affected by the high-pressure turbine disc rub-impact and are mainly affected by the high-pressure compressor disc unbalance.

\section{Data Availability}

The data used to support the findings of this study are included within the article.

\section{Conflicts of Interest}

The authors declare no conflicts of interest.

\section{Acknowledgments}

This research was supported by the Key Laboratory of Vibration and Control of Aero-Propulsion System Ministry of Education, Northeastern University (VCAME201801 and VCAME201903).

\section{References}

[1] Y. Chen and H. Zhang, "Research progress and prospect of aero-engine overall dynamics," Journal of Aviation, vol. 32, no. 8, pp. 1371-1391, 2011.

[2] H. Zhang, "Reverse full-circumferential rub-impact response of a non-linear rotor," Journal of Vibration and Shock, vol. 32, no. 10, pp. 84-90, 2013.

[3] H. Zhang, Y. Chen, and J. Li, "Bifurcation response of elastic support-rigid rotor system to synchronous full-circumferential rubbing," Applied Mathematics and Mechanics, vol. 33, no. 7, pp. 865-880, 2012.

[4] L. Yan and D. Wang, "Research on the vibration characteristics of aero dual-rotor engine rubbing against static parts," Journal of Aeronautical Dynamics, vol. 5, no. 2, pp. 173-176, 1998.

[5] S. Wang, M. Liao, Y. Jiang et al., "Local rubbing failure experiment of counter-rotating dual-rotors," Propulsion Technology, vol. 34, no. 1, pp. 31-36, 2013.

[6] X. Deng, M. Liao, R. Liebich et al., "Experimental research on bending and torsional vibration of the double-disc rotor with rub-impact," Journal of Aeronautics and Dynamics, vol. 14, no. 2, pp. 205-211, 2002.

[7] Y. Wang, L. Wang, M. Liao et al., "Research on the vibration characteristics of dual-rotor engine rotor-casing rubbing," Mechanical Science and Technology, vol. 33, no. 4, pp. 614-620, 2014.

[8] Q. K. Han, H. T. Luo, and B. C. Wen, "Simulations of a dualrotor system with local rub-impacts based on rigid-flexible multi-body model," Key Engineering Materials, vol. 413-414, p. $677,2009$.

[9] Q. Han, H. Duan, and Z. Luo, "Sensitivity analysis of the rubimpact of internal and external dual-rotor systems," in Proceedings of the National Conference on Vibration Theory and Application, Deshmukhi, Telangana, India, December 2011.
[10] Q. Han, Non-linear Vibration Analysis and Diagnosis Method of Faulty Rotor System, Science Press, Beijing, China, 2010.

[11] G. Luo, X. Yang, and F. Wang, "Research on the rub-impact response characteristics of high-dimensional dual-rotor systems," Journal of Vibration Engineering, vol. 28, no. 1, pp. 100-107, 2015.

[12] C. Guo, "A new type of rotor-rolling bearing-casing coupling dynamic model with rubbing faults," Chinese Journal of Vibration Engineering, vol. 22, no. 5, pp. 539-545, 2009.

[13] G. Wang, Research on the Dynamics of Aero-Engine DualRotor Rub-Impact, Harbin Institute of Technology, Harbin, China, 2010.

[14] X. Liu, Q. Li, and D. Wang, “The dynamic model and wavelet transform characteristics of a dual-rotor system with rotating and static parts rubbing faults," Journal of Aeronautical Dynamics, vol. 15, no. 2, pp. 76-79, 2000.

[15] N. Wang, D. Jiang, T. Han et al., "Research on the dynamics of static and dynamic rubbing of a dual-rotor system and experimental verification based on vibration acceleration," Journal of Vibration and Shock, vol. 36, no. 14, pp. 71-76, 2017.

[16] T. Zhang, S. Cao, L. Li et al., "Analysis and experiment of coupled flexural-torsional vibration of a rub-impact dualrotor system," Journal of Aeronautical Dynamics, vol. 34, no. 3, pp. 138-150, 2019.

[17] Y. Ouyang and M. Yang, "Research on vibration characteristics of the aero-engine dual-rotor system with the rubimpact fault," Mechanical Engineer, no. 11, pp. 65-71, 2016.

[18] H. Zhang, Research on Nonlinear Dynamics of Aero-Engine Rotor System with Rub-Impact, Harbin Institute of Technology, Harbin, China, 2012.

[19] G. Liu, Research on the Dynamic Characteristics of a DualRotor System with Typical Faults, Northeastern University, Boston, MA, USA, 2012.

[20] P. Ma, J. Zhai, H. Zhang, and Q. Han, "Multi-body dynamic simulation and vibration transmission characteristics of the dual-rotor system for aero-engine with rubbing coupling faults," Journal of Vibroengineering, vol. 21, no. 7, pp. 1875-1887, 2019.

[21] H. Yuan, W. He, and Q. Han, "Analysis of rubbing faults of engine dual-rotor-cases coupling system," Journal of Aerodynamics, vol. 26, no. 11, pp. 2401-2408, 2011.

[22] P. Ma, H. Zhang, J. Zhai, G. Wei, and Q. Han, "Multi-body dynamic simulations of unbalance induced vibration and transfer characteristics of the inner and outer dual-rotor system in aero-engine," International Journal of Smart Engineering, vol. 2, no. 1, pp. 104-122, 2018.

[23] K. C. Lee, D. K. Hong, Y. H. Jeong, C. Y. Kim, and M. C. Lee, "Dynamic simulation of the radial active magnetic bearing system for high-speed rotor using ADAMS and MATLAB cosimulation," in Proceedings of the 2012 IEEE International Conference on Automation Science \& Engineering, Seoul, Korea (South), August 2012.

[24] S. Wang, Z. Deng, D. Yang, Y. Tang, and X. Wang, "ADAMS simulation research on the new structure of lunar lander," Journal of Harbin Institute of Technology, vol. 39, no. 9, pp. 1392-1394, 2007.

[25] F. Fritz, A. Basler, and W. Seemann, "Simulation of highspeed ball bearings with MSC/ADAMS," PAMM, vol. 9, no. 1, pp. 115-116, 2010.

[26] F. Chen, ADAMS 2012 Virtual Prototype Technology from Entry to Proficiency, Tsinghua University Press, Beijing, China, 2013. 
[27] W. Zhao, Z. Shi, and F. Dai, ADAMS2013 Basic and Application Examples Course, Tsinghua University Press, Beijing, China, 2015.

[28] X. Shan, X. U. Long, Z. Yunlai, Z. Bo, M. Haifeng, and Y. Haoran, "Comparative analysis of Hertz contact simulation based on Adams and RecurDyn," Journal of Changchun University of Science and Technology (Natural Science Edition), vol. 39, no. 4, pp. 73-86, 2016.

[29] C. Sun, Y. Chen, and L. Hou, "Steady-state response characteristics of a dual-rotor system induced by rub-impact," Nonlinear Dynamics, vol. 86, no. 1, pp. 91-105, 2016.

[30] C. Sun, Y. Chen, and L. Hou, "Nonlinear dynamical behaviors of a complicated dual-rotor aero-engine with rub-impact," Archive of Applied Mechanics, vol. 88, no. 8, pp. 1305-1324, 2018.

[31] Y. Yang, D. Cao, D. Wang, and G. Jiang, "Fixed-point rubbing characteristic analysis of a dual-rotor system based on the Lankarani-Nikravesh model," Mechanism and Machine Theory, vol. 103, pp. 202-221, 2016.

[32] Y. Yang, D. Cao, T. Yu, D. Wang, and C. Li, "Prediction of dynamic characteristics of a dual-rotor system with fixed point rubbing-Theoretical analysis and experimental study," International Journal of Mechanical Sciences, vol. 115-116, pp. 253-261, 2016. 